CARLOS HENRIQUE MACIEL BRUNNER

Avaliação do comportamento vascular do tumor de Ehrlich na forma sólida em camundongos submetidos à eletroquimioterapia com bleomicina

São Paulo 2015 
CARLOS HENRIQUE MACIEL BRUNNER

\section{Avaliação do comportamento vascular do tumor de Ehrlich na forma sólida em camundongos submetidos à eletroquimioterapia com bleomicina}

Tese apresentada ao Programa de PósGraduação em Anatomia dos Animais Domésticos e Silvestres da Faculdade de Medicina Veterinária e Zootecnia da Universidade de São Paulo para obtenção do título de Doutor em Ciências

\section{Departamento:}

Cirurgia

Área de concentração:

Anatomia dos Animais Domésticos e Silvestres

Orientador: Prof. Dr. Vicente Borelli 
Autorizo a reprodução parcial ou total desta obra, para fins acadêmicos, desde que citada a fonte.

\section{DADOS INTERNACIONAIS DE CATALOGAÇÃO-NA-PUBLICAÇÃO}

(Biblioteca Virginie Buff D’Ápice da Faculdade de Medicina Veterinária e Zootecnia da Universidade de São Paulo)

Brunner, Carlos Henrique Maciel

Avaliação do comportamento vascular do tumor de Ehrlich na forma sólida em camundongos submetidos à eletroquimioterapia com bleomicina / Carlos Henrique Maciel Brunner. -- 2015

$75 \mathrm{f}$. : il.

Tese (Doutorado) - Universidade de São Paulo. Faculdade de Medicina Veterinária e Zootecnia. Departamento Cirurgia, São Paulo, 2015.

Programa de Pós-Graduação: Anatomia dos Animais Domésticos e Silvestres.

Área de concentração: Anatomia dos Animais Domésticos e Silvestres.

Orientador: Prof. Dr. Vicente Borelli.

1. Eletrquimioterapia. 2. Bleomicina. 3. Vascularização. 4. Resveratrol. 5. Tumor de Ehrlich. I. Título. 


\title{
CERTIFICADO
}

Certificamos que o Projeto intitulado "Avaliação do comportamento vascular do tumor de Ehrlich na forma sólida em camundongos submetidos à eletroquimioterapia com bleomicina", protocolado sob o CEUA $n^{\circ} 7922220615$, sob a responsabilidade de Prof Dr Vicente Borelli e equipe; Carlos Henrique Maciel Brunner - que envolve a produção, manutenção e/ou utilização de animais pertencentes ao filo Chordata, subfilo Vertebrata (exceto o homem), para fins de pesquisa científica (ou ensino) - encontra-se de acordo com os preceitos da Lei 11.794, de 8 de outubro de 2008, com o Decreto 6.899, de 15 de julho de 2009, com as normas editadas pelo Conselho Nacional de Controle da Experimentação Animal (CONCEA), e foi aprovado pela Comissão de Ética no Uso de Animais da Faculdade de Medicina Veterinária e Zootecnia da Universidade de São Paulo (CEUA/FMZV) em reunião de 01/07/2015.

We certify that the proposal "Evaluation of vascular behavior of Ehrlich tumor in solid form in mice submitted to electrochemotherapy with bleomycin. ", utilizing 50 Heterogenics mice $(50$ females), protocol number CEUA 7922220615, under the responsibility of Prof Dr Vicente Borelli and team; Carlos Henrique Maciel Brunner - which involves the production, maintenance and/or use of animals belonging to the phylum Chordata, subphylum Vertebrata (except human beings), for scientific research purposes (or teaching) - it's in accordance with Law 11.794, of October 8 2008, Decree 6899, of July 15, 2009, with the rules issued by the National Council for Control of Animal Experimentation (CONCEA), and was approved by the Ethic Committee on Animal Use of the School of Veterinary Medicine and Animal Science of São Paulo University (CEUA/FMZV) in the meeting of 07/01/2015.

Vigência da Proposta: de 2013 a 2014

Área: Departamento De Cirurgia

Procedência: Biotério da Universidade Paulista, campus Indianópolis

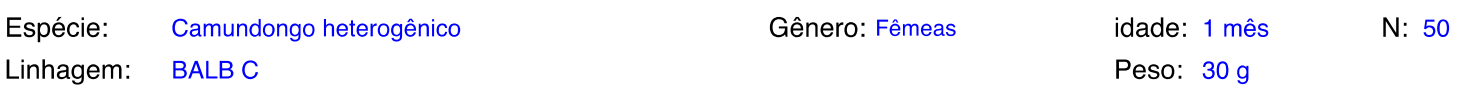

\author{
Sering \& ondin \\ Profa. Dra. Denise Tabacchi Fantoni \\ Presidente da Comissão de Ética no Uso de Animais \\ Faculdade de Medicina Veterinária e Zootecnia \\ Universidade de São Paulo
}




\section{CERTIFICA D O}

CERTIFICAMOS, que o protocolo $n^{\circ}$ 018/10 CEP/ICS/UNIP, sobre o projeto de pesquisa intitulado" EFEITO DA ELETROQUIMIOTERAPIA SOBRE O DESENVOLVIMENTO DO TUMOR DE EHLICH NA FORMA SÓLIDA EM CAMUDONGOS E SUAS REPERCURSÕES SOBRE OS TECIDOS LINFÓIDES" "JOSE GUILHERME XAVIER, está de acordo com os Princípios Éticos, seguindo as diretrizes e normas regulamentadoras de pesquisa envolvendo animais, conforme a Lei Estadual n ${ }^{\circ} 11.977 / 05$ que institui o Código de Proteção aos Animais do Estado de São Paulo e foi aprovado por este Comitê de Ética em Pesquisa.

Universidade Paulista, em São Paulo-SP, aos 16 dias do mês de setembro de 2010.

\section{Hailuy Barres F. Gonçotres \\ Hailey Barros F. Gonçalves \\ Secretária do Comitê de Ética em Pesquisa da UNIP}

Campus: INDIANÓPOLIS

Rua: Doutor Bacelar, 1212 - Vila Clementino - São Paulo - SP - CEP: 04026-000

Fone: (11) 5586-4091 - Fax: (11) 5586-4073

E-mail: cep@unip.br - http://www.unip.br 


\title{
C ERTIFIC A D O
}

CERTIFICAMOS, que o protocolo $n^{\circ}$ 196/13 CEP/ICS/UNIP, sobre o projeto de pesquisa intitulado" Efeito da eletroquimioterapia e de sua combinação com o reveratrol sobre o desenvolvimento do tumor de Ehrlich na forma sólida em camundongos "JOSE GUILHERME XAVIER e Ediquel Sena de Carvalho Junior, está de acordo com os Princípios Éticos, seguindo as diretrizes e normas regulamentadoras de pesquisa envolvendo animais, conforme a Lei Estadual $n^{\circ}$ 11.977/05 que institui o Código de Proteção aos Animais do Estado de São Paulo e foi aprovado por este Comitê de Ética em Pesquisa.

Universidade Paulista, em São Paulo-SP, aos 16 dias do mês de setembro de 2010.

\author{
Haily Barwes F. Gonçahes \\ Hailey Barros F. Gonçalves \\ Secretária do Comitê de Ética \\ em Pesquisa da UNIP
}

Campus: INDIANÓPOLIS

Rua: Doutor Bacelar, 1212 - Vila Clementino - São Paulo - SP - CEP: 04026-000

Fone: (11) 5586-4091 - Fax: (11) 5586-4073

E-mail: cep@unip.br - http://www.unip.br 


\section{FOLHA DE AVALIAÇÃO}

Autor: BRUNNER, Carlos Henrique Maciel

Título: Avaliação do comportamento vascular do tumor de Ehrlich na forma sólida em camundongos submetidos à eletroquimioterapia com bleomicina

Tese apresentada ao Programa de PósGraduação em em Anatomia dos Animais Domésticos e Silvestres da Faculdade de Medicina Veterinária e Zootecnia da Universidade de São Paulo para obtenção do titulo de Doutor em Ciências

Data:

\section{Banca Examinadora}

Prof. Dr.

Instituição: Julgamento:

Prof. Dr.

Instituição: Julgamento:

Prof. Dr.

Instituição: Julgamento:

Prof. Dr.

Instituição: Julgamento:

Prof. Dr. Instituição: Julgamento: 


\section{DEDICATÓRIA}

Ao Bruno, Caio, Leo e principalmente a minha esposa Gisele, minha linda família, que souberam entender meu distanciamento temporário, mas que acima de tudo me oferecem todo dia o amor e a alegria de viver. 


\section{AGRADECIMENTOS}

Ao Prof. Dr. Vicente Borelli, meu professor de anatomia na graduação, meu Coordenador na Universidade Paulista há 23 anos e que agora me propiciou a honra de tê-lo como orientador. Sem seu incentivo, apoio incondicional e sua sabedoria nada disso teria sido possível;

Ao Prof. Dr. José Guilherme Xavier, que me orientou em toda área técnica e muito me ensinou nos caminhos da patologia. A ele, minha imensa gratidão;

A Profa. Dra. Maria de Fátima Monteiro Martins, a quem muito agradeço não só pelo apoio no decorrer desse período de doutoramento, mas sim por toda amizade em todos nossos anos de trabalho conjunto;

A Profa. Dra. Maria Angélica Miglino por ter me recebido, seu ex-aluno de graduação na Anatomia da FMVZ USP, abrindo fraternalmente as portas do Departamento;

A Profa. Dra. Stefanie Vanessa Santos pela ajuda com os procedimentos imunohistológicos no Hospital AC Camargo e apoio na condução de nossa disciplina na Universidade Cruzeiro do Sul;

Ao Prof. Ms. João Paulo Boccia que com seu ânimo inabalável me impulsionou nesse caminho e conduziu com destreza nossa disciplina na Universidade Paulista em momentos de minha ausência;

A Profa. Ms. Lucia Maria Guedes Silveira que caminha comigo desde o primeiro paciente atendido em 2007 dando início ao nossa grupo de estudo da eletroquimioterapia;

A todos os técnicos e demais funcionários da Universidade Paulista e da FMVZ da Universidade de São Paulo que me auxiliaram e tornaram esse trabalho possível, a eles meu muito obrigado. 
Nascia conceitualmente a quimioterapia:

"Ocorreu-me que (...) deve ser possível encontrar substâncias artificiais que curam certas doenças verdadeiras e especificamente, e não são apenas paliativos que agem de forma positiva num ou noutro sintoma"

Paul Ehrlich em 1882, aos 28 anos de idade. 


\section{RESUMO}

BRUNNER, C. H. M. Avaliação do comportamento vascular do tumor de Ehrlich na forma sólida em camundongos submetidos à eletroquimioterapia com bleomicina. [Evaluation of vascular behavior of Ehrlich tumor in solid form in mice submitted to electrochemotherapy with bleomycin]. 2015. $75 \mathrm{f}$. Tese (Doutorado em Ciências) - Faculdade de Medicina Veterinária e Zootecnia, Universidade de São Paulo, São Paulo, 2015.

A eletroquimioterapia (EQT) é uma modalidade de tratamento recente que se baseia na associação de quimioterápicos potencializados pela eletroporação. Possui indicação para neoplasias sólidas de origens histológicas distintas, apresentando baixa morbidade e elevada eficiência. A ação da EQT ocorre em múltiplos sítios, tanto envolvendo a quebra da molécula de DNA, quanto exercendo efeito sobre a vasculatura tumoral. No presente estudo buscou-se maior compreensão dos eventos vasculares, avaliando-se qualitativamente e quantitativamente, com auxílio de marcação imunológica, com fator VIII e VEGF-A, a vascularização do tumor de Ehrlich implantado na forma sólida em camundongos, não tratados e submetidos à EQT com bleomicina, após sete dias de tratamento. No intuito de melhor elucidar os fenômenos vasculares, também foi investigado o efeito do resveratrol associado à EQT. O resveratrol, presente em vegetais como as uvas, possui efeitos de inibição do HIF1- $\alpha$, reconhecida proteina que estimula a angiogênese em condições de hipoxia tumoral. Os animais submetidos à quimioterapia com bleomicina não apresentaram redução de volume tumoral, ao contrário dos que sofreram EQT com o mesmo fármaco. Evidenciou-se maior densidade microvascular tumoral em animais tratados com quimioterapia, quando comparados aos não tratados e aos submetidos à EQT. O tratamento com resveratrol diminuiu a expressão de VEGF-A e obteve efeito mais pronunciado quando associado à EQT com bleomicina. Através dos fenômenos pesquisados pôde-se evidenciar que a EQT com bleomicina foi efetiva na redução do volume do tumor de Ehrlich e que houve redução da atividade proliferativa assim como da densidade microvascular tumoral. Também observou-se que o resveratrol, ainda mais quando associado à EQT com bleomicina, reduz a proliferação tumoral e a expressão de VEGF-A.

Palavras-chave: Eletroquimioterapia. Bleomicina. Vascularização. Resveratrol. Tumor de Ehrlich. 


\begin{abstract}
BRUNNER, C. H. M. Evaluation of vascular behavior of Ehrlich tumor in solid form in mice submitted to electrochemotherapy with bleomycin. [Avaliação do comportamento vascular do tumor de Ehrlich na forma sólida em camundongos submetidos à eletroquimioterapia com bleomicina]. 2015. 75 f. Tese (Doutorado em Ciências) - Faculdade de Medicina Veterinária e Zootecnia, Universidade de São Paulo, São Paulo, 2015.
\end{abstract}

The electrochemotherapy (EQT) is a new treatment modality based on the association of chemotherapy potentiated by electroporation. Has indication for solid neoplasms of histological distinct origins, presenting low morbidity and high efficiency. The action of the EQT occurs in multiple sites, both involving the breakage of the DNA molecule, as having an effect on the tumor vasculature. The present study aimed at better understanding of vascular events, evaluating qualitatively and quantitatively, using immune labeling, with factor VIII and VEGF-A, the vascularization of the Ehrlich tumor implanted in solid form in mice, untreated and submitted to EQT with bleomycin, after seven days of treatment. In order to better elucidate the vascular phenomena, was also investigated the effect of resveratrol associated with EQT. The resveratrol present in plants such as grapes, has inhibitory effects of HIF1- $\alpha$, a protein that is recognized to stimulates angiogenesis in tumor hypoxia. The animals submitted to chemotherapy with bleomycin showed no reduction of tumor volume, unlike those who suffered EQT with the same drug. It was evidenced increased microvessel density tumor in animals treated with chemotherapy, when compared to untreated and those submitted to EQT. The treatment with resveratrol decreased the expression of VEGF-A and obtained effect was more pronounced when associated to the EQT with bleomycin. This research can prove that the EQT with bleomycin was effective in reducing the volume of Ehrlich tumor and that there was a reduction of proliferative activity as well as of microvascular density tumor. Also it was observed that the resveratrol, even more when associated with EQT with bleomycin, reduces the tumor proliferation and the expression of VEGF-A.

Keywords: Electrochemotherapy. Bleomycin. Vascularization. Resveratrol. Ehrlich tumor. 


\section{LISTA DE FIGURAS}

Figura 1 - Camundongo portador de tumor de Ehrlich na forma ascítica sendo submetido à punção do líquido ascítico para transplante tumoral.

Figura 2 - Amostras de células neoplásicas do tumor de Ehrlich .20

Figura 3 - As fases da eletroporação da membrana citoplasmática 22

Figura 4 - Fotomicrografia de corte histológico do tumor de Ehrlich. .43

Figura 5 - Fotomicrografia de corte histológico de tumor de Ehrlich sólido em animal submetido à quimioterapia com bleomicina

Figura 6 - Fotomicrografias de tumor de Ehrlich na forma sólida, hematoxilina-eosina, $40 \mathrm{x}$

Figura 7 - Fotomicrografias de tumor de Ehrlich na forma sólida, DAB contra-corado com hematoxlina de Harris, 40x 


\section{LISTA DE TABELAS}

Tabela 1 - Evolução do peso dos camundongos BALB-c durante 7 dias de experimentação

Tabela 2 - Evolução tumoral dos camundongo BALB-c com tumor de Ehrlich em forma sólida após 7 dias de experimentação .42

Tabela 3 - Densidade microvascular tumoral em animais portadores do tumor de Ehrlich na forma sólida, dos grupos controle, quimioterapia e eletroquimioterapia

Tabela 4 - Evolução do volume tumoral de camundongos BAB-c portadores do tumor de Ehrlich na forma sólida em 7 dias .59

Tabela 5 - Media da atividade proliferativa por grupo, a partir da contagem de mitoses em 10 campos de grande aumento

Tabela 6 - Avaliação da imunomarcação com VEGF-A em camundongos portadores do tumor de Ehrlich na forma sólida em 7 dias 


\section{LISTA DE GRÁFICOS}

Gráfico 1 - Evolução tumoral no período de 7 dias em camundongos BAB-c portadores de tumor de Ehrlich na forma sólida sem tratamento, tratados com quimioterapia ou tratado com eletroquimioterapia

Gráfico 2 - Densidade microvascular tumoral em camundongos portadores do tumor de Ehrlich na forma sólida, tratados com quimioterapia, eletroquimioterapia e controle

Gráfico 3 - Desenvolvimento neoplásico do tumor de Ehrlich na forma sólida em camundongos BAB-c em 7 dias .60 


\section{SUMÁRIO}

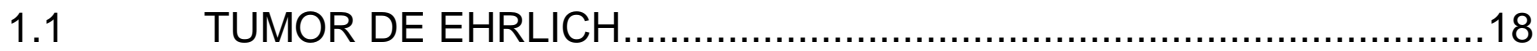

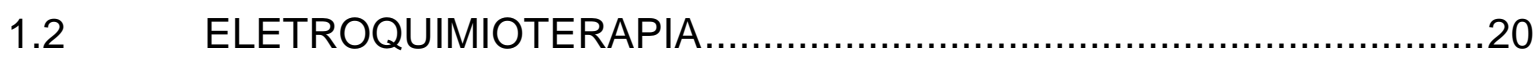

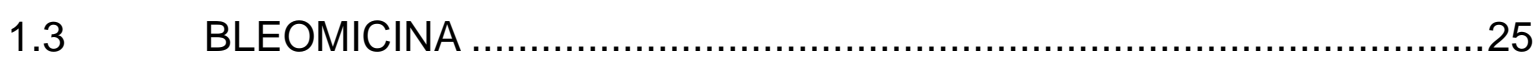

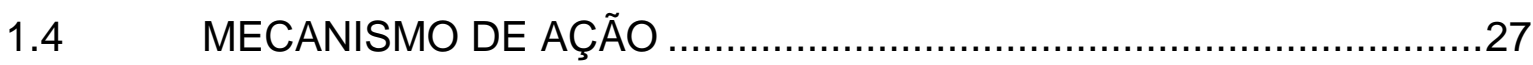

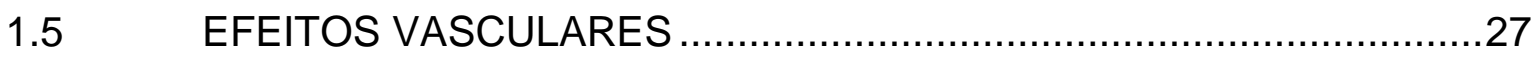

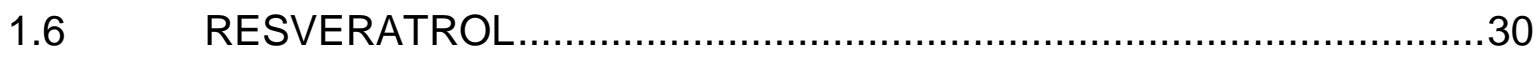

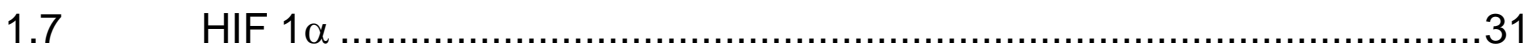

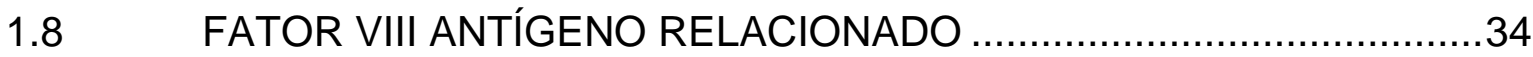

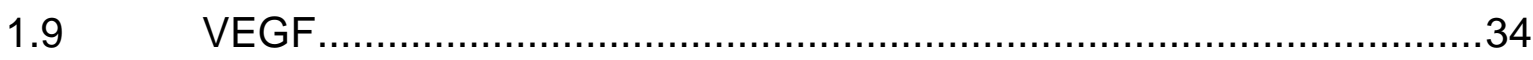

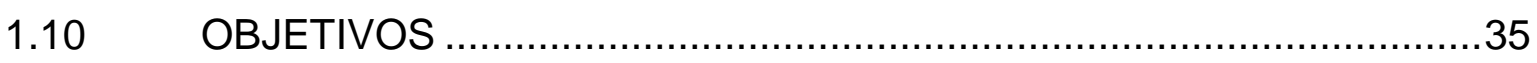

2

AVALIAÇÃO DA VASCULATURA DO TUMOR DE EHRLICH NA FORMA SÓLIDA EM CAMUNDONGOS TRATADOS COM ELETROQOUIMIOTERAPIA COM BLEOMICINA ............................36

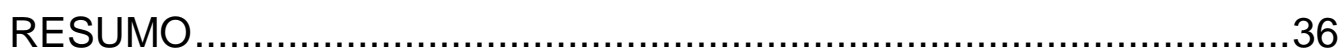

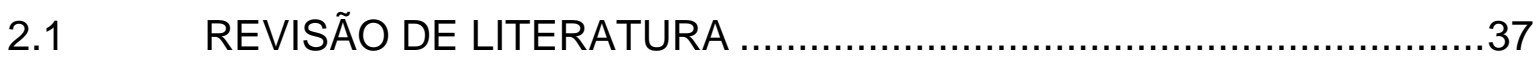

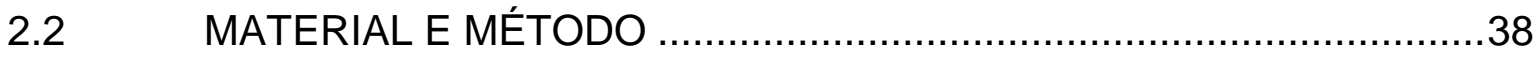

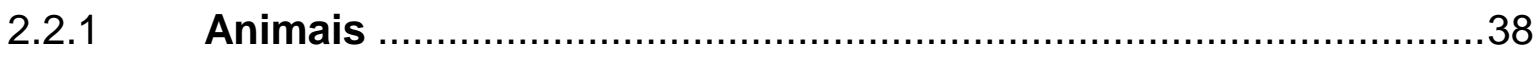

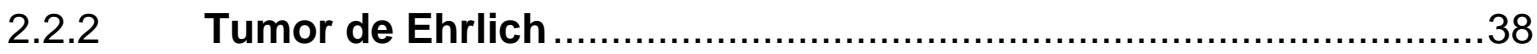

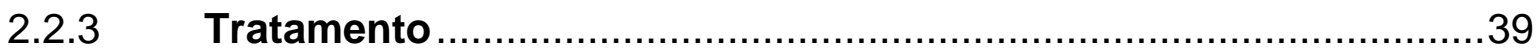

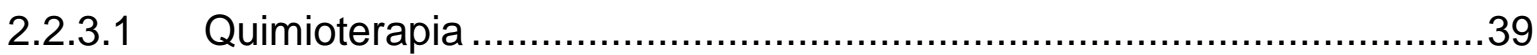

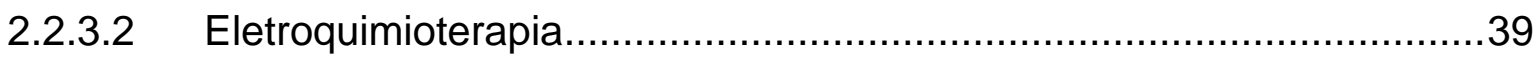

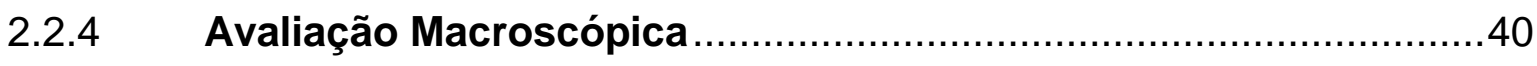

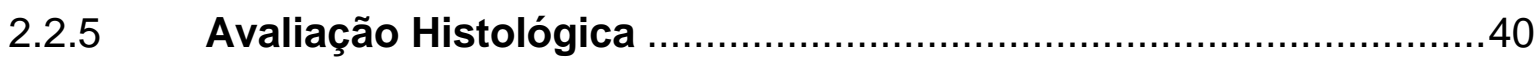

2.2.6 Procedimento Imuno-Histoquímico ………................................40

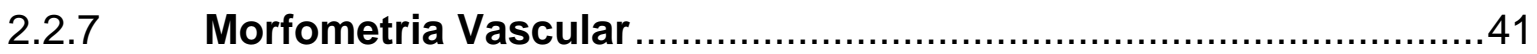

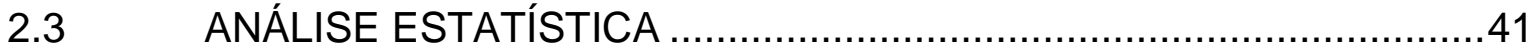

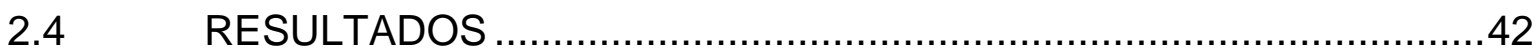

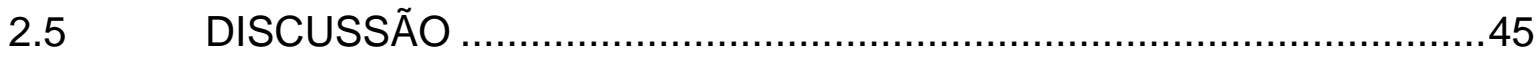

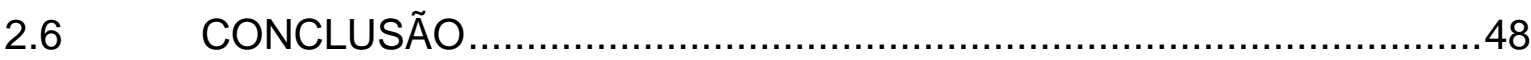


EFEITO DA ELETROQUIMIOTERAPIA E DE SUA COMBINAÇÃO COM O RESVERATROL SOBRE O DESENVOLVIMENTO DO TUMOR DE EHRLICH NA FORMA SÓLIDA EM CAMUNDONGOS . .53

RESUMO. .53

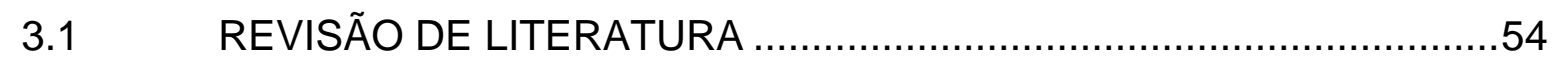

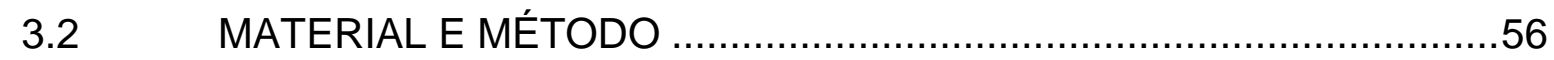

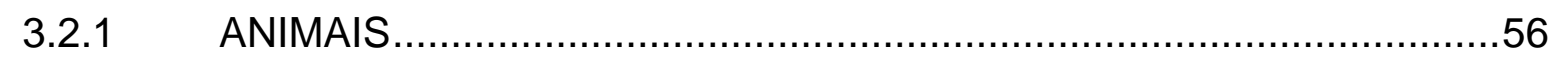

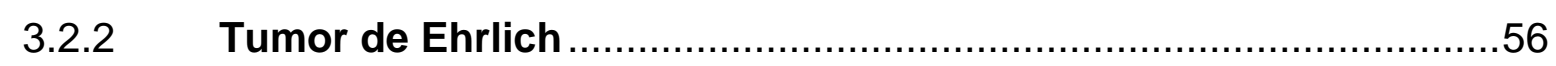

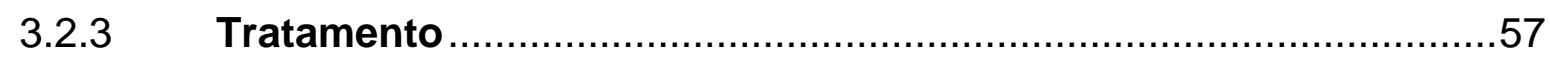

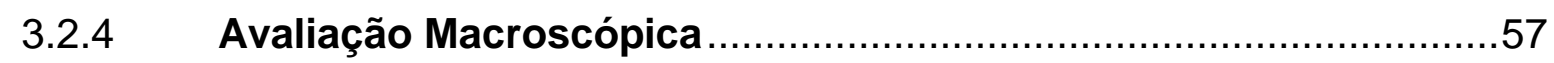

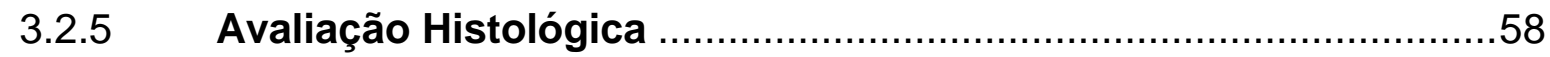

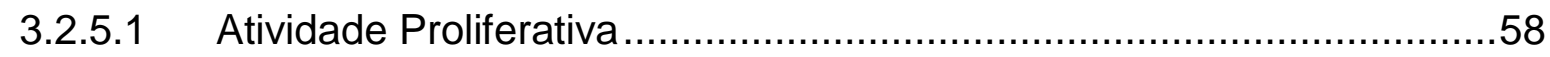

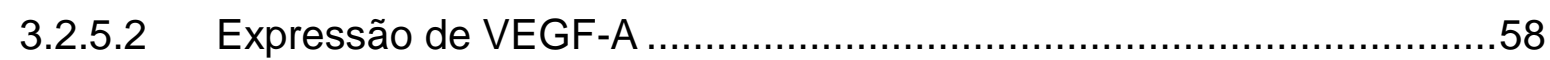

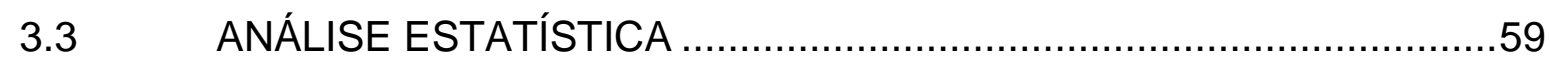

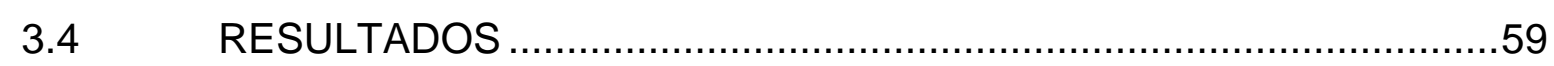

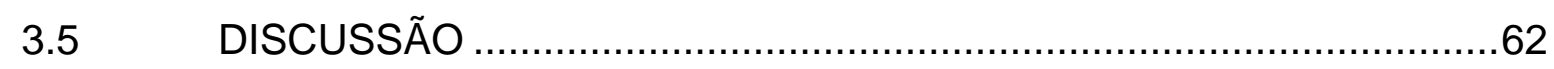

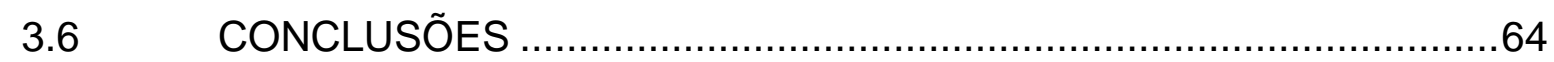

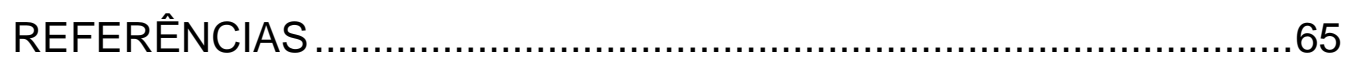

$4 \quad$ CONCLUSÃO GERAL

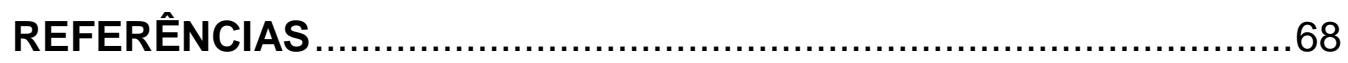




\section{INTRODUÇÃO GERAL}

\subsection{TUMOR DE EHRLICH}

Grande parte da compreensão dos mecanismos envolvidos no desenvolvimento de uma neoplasia ocorreu após o surgimento da oncologia experimental, que se originou com a introdução dos chamados tumores transplantáveis. Esses são tumores de animais mantidos em laboratório mediante do transplante de suas células a hospedeiros susceptíveis (VERLENGIA, 1994).

Um impulso dentro do estudo dos tumores experimentais foi a conversão da forma sólida dos tumores para a forma ascítica: as células do tumor livres ou complexos de células crescem ativamente no fluido peritoneal, induzindo o acúmulo ascítico, alcançando alta concentração celular, possibilitando seu estudo sob vários aspectos como citológico, bioquímico, genético e imunológico. A manutenção destes tumores é feita pela passagem de fluído ascítico de um animal a outro, com a utilização de meios de cultura apropriados ou de técnicas de congelação (VERLENGIA, 1994).

Nos primeiros trabalhos experimentais, os tumores eram transplantados para um grande número de animais, sendo que a positividade de desenvolvimento era pequena. Entretanto, atualmente, sabe-se que essas neoplasias estabilizam-se após passagens sucessivas, mantendo suas características por várias gerações, sendo encontrados na literatura verdadeiros tratados sobre os tipos de tumores transplantáveis onde linhagens são classificadas de acordo com o tecido de origem e a espécie animal em que se desenvolveram (DUNHAM; STEWART, 1953). São utilizados em estudos da ação de componentes químicos, físicos e biológicos sobre seu crescimento, além de estudos de citogenética, patogênese, imunologia, bioquímica e terapêutica das células tumorais (LINO, 2002).

Nessa linha de investigação, um dos modelos experimentais mais estudados foi o tumor de Ehrlich por ser um dos primeiros tumores transplantáveis conhecidos, descrito por Paul Ehrlich em 1905. Trata-se de neoplasia originária de carcinoma mamário de camundongos fêmeas, transplantado em camundongos, inicialmente na 
forma sólida (HARTVEIT, 1966). A conversão para a forma ascítica, após inoculação intraperitoneal de células do tumor sólido foi descrita nos anos 1930 quando também se evidenciou que o tempo de sobrevida do animal, bem como a rapidez do desenvolvimento do processo, dependem do número de células inoculadas (MAYER, 1966).

A conversão do tumor de Ehrlich para forma ascítica (Figura 1) trouxe vantagens como a possibilidade da padronização do número de células inoculadas (Figura 2), a quantificação da regressão e do crescimento tumoral, bem como o estudo da célula tumoral propriamente dita (DUNHAM; STEWART, 1953).

Pela dificuldade na obtenção de número suficiente de animais com linhagens e idades uniformes, os pesquisadores tentaram manter os tumores in vivo em animais cuja linhagem fosse diferente daquela na qual se originou, o que só foi possível após muitos transplantes sucessivos, tendo o tumor deixado de expressar seus genes de histocompatibilidade, passando a crescer em animais de genótipos diferentes. Este tipo de tumor é usualmente referido como não específico, incluindo entre eles o tumor de Ehrlich (LINO, 2002).

Figura 1 - Camundongo portador de tumor de Ehrlich na forma ascítica sendo submetido à punção do líquido ascítico para transplante tumoral

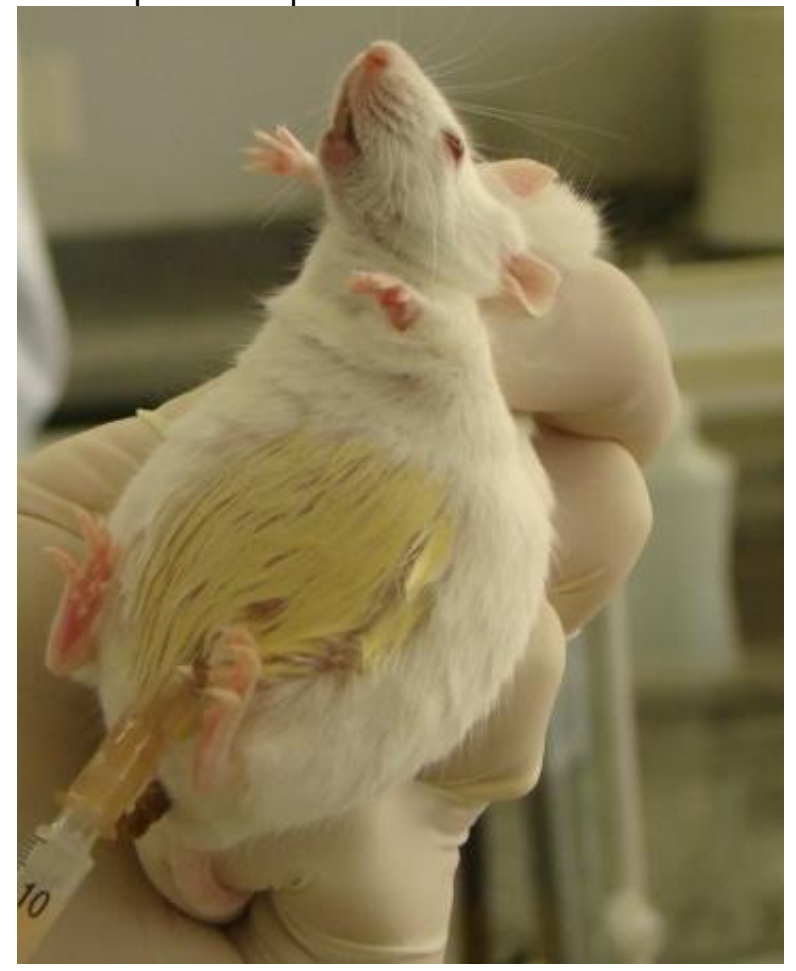

Fonte: XAVIER, J.G. 
Figura 2 - Amostras de células neoplásicas do tumor de Ehrlich

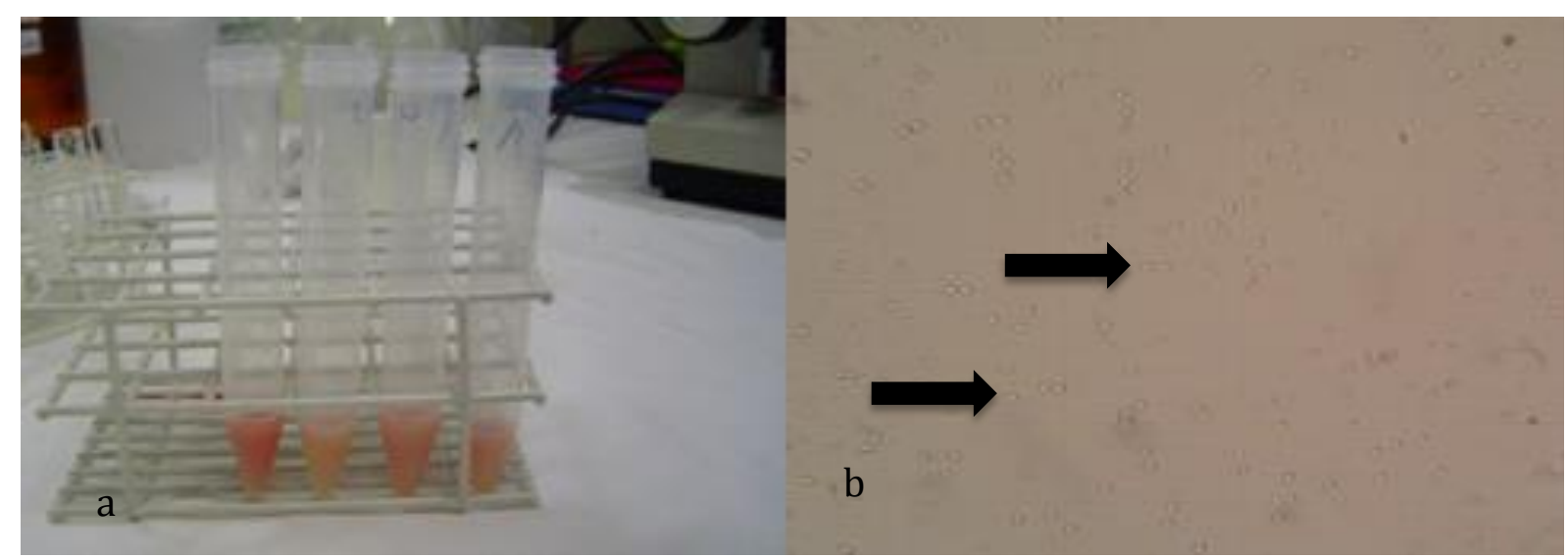

Fonte: XAVIER, J.G.

Em "a" no líquido ascítico; em "b" em câmara de Neubauer para contagem (setas), obj. 10x.

\subsection{ELETROQUIMIOTERAPIA}

A eletroquimioterapia (EQT) consiste em técnica que combina a administração de agentes antineoplásicos hidrofílicos pelas via intravenosa ou intratumoral, e a aplicação de pulsos elétricos de alta voltagem e de curta duração, com formato de onda adequado, objetivando a aumentar a captação dos quimioterápicos pelas células tumorais por meio da eletroporação (MIR et al., 1991; MALI et al., 2013).

A membrana citoplasmática é constituída por matriz fluida de fosfolipídios dispostos de maneira ordenada. As cabeças polares dos fosfolipídios estão justapostas lateralmente e voltadas para o meio aquoso, seja ele extra ou intracelular, e as caudas lipídicas e apolares, voltadas contra as outras caudas de mesma natureza. Essa estrutura da membrana celular atua como barreira fortemente impermeável à penetração de moléculas exógenas no citoplasma, principalmente as não lipídicas. Apenas um limitado número de compostos pode entrar na célula por difusão simples ou mediante transporte específico, as custas de gasto de energia (ROLS; TEISSIÉ, 1990).

A bicamada de fosfolipídios da membrana confere, entre outras, duas características relevantes à EQT. A baixa permeabilidade a íons por difusão permite que se criem gradientes de concentração entre os meios extracelular e o citosol, 
armazenando potenciais elétricos. No mesmo sentido a torna com baixa condutibilidade elétrica e mimetiza um sistema capacitor, capaz de armazenar diferenças de potenciais elétricos. Quando submetida a significativas diferenças de potenciais elétricos, ocorre movimento de íons ao longo dos campos elétricos quando da polarização, provocando intensa perturbação do equilíbrio eletrogênico das células (TEISSIE; TSONG, 1981).

Sob a ação de campos elétricos na forma de pulsos, ocorre migração de íons e moléculas polares entre o catodo e o anodo. Se essa movimentação de partículas ocorrer contra a membrana citoplasmática, sob circunstâncias elétricas específicas, ocorre a penetração de moléculas de água entre as caudas lipídicas dos fosfolipídios, criando um pré-poro, ainda hidrofóbico. Com a persistência dos pulsos elétricos parametrizados, ocorre rearranjo das cabeças polares, e portanto hidrofílicas, contra o interior da espessura da própria membrana citoplasmática, gerando um poro hidrofílico no fenômeno denominado eletroporação, ou simplesmente poração (GIARDINO et al., 2006).

A eletroporação ocorre quando o potencial elétrico transmembrana alcança valores críticos, e pode ser dividida em quatro fases (Figura 3) (TEISSIÉ et al., 2012):

a) Indução (escala de tempo de microssegundo ou menos): O campo elétrico induz alteração no potencial de membrana e tende a provocar defeitos quando atinge ao redor de $200 \mathrm{mV}$;

b) Expansão (micro a milissegundo): o defeito se expande por tempo proporcional à presença do campo elétrico;

c) Estabilização (milissegundo): com a redução do campo elétrico ocorre estabilização do processo tendo a membrana se tornado permeável a pequenas moléculas;

d) Selamento (minuto): O membrana volta a ser selada em um processo lento (resealing). 
Figura 3 - As fases da eletroporação da membrana citoplasmática

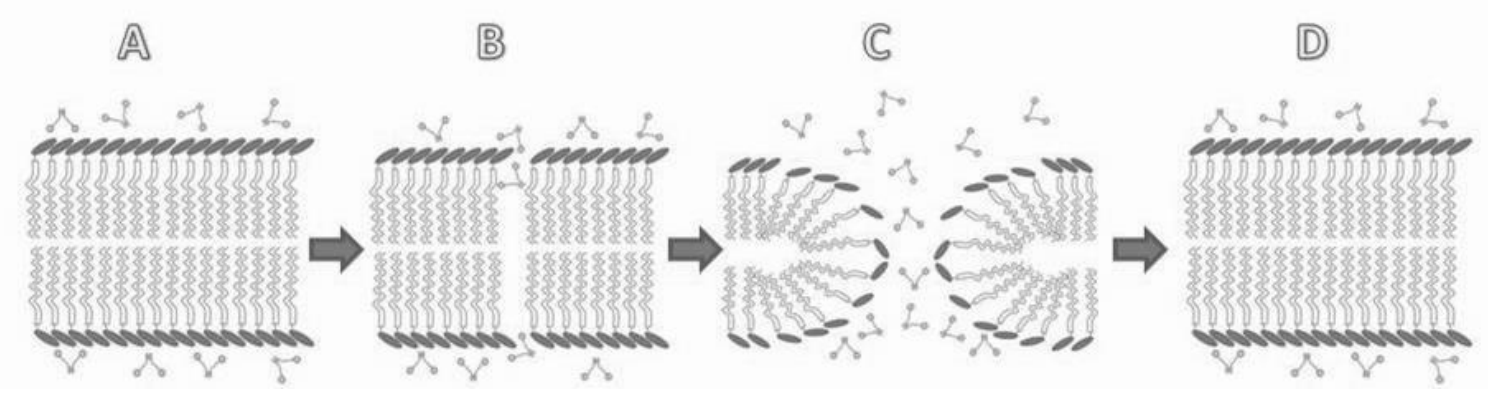

Fonte: (BRUNNER ${ }^{1}$ )

A entrada de pequenas moléculas hidrofóbicas ocorre basicamente por processo de difusão após a poração (TEISSIÉ et al., 2012). A facilitação da penetração de pequenas moléculas por meio eletroforético também pode ocorrer durante a permanência dos pulsos elétricos, porém persiste durante o selamento da membrana, que por ocorrer por muito mais tempo que a duração do pulso assume maior importância (PUCIHAR et al., 2008) .

$O$ carregamento passivo durante o selamento lento permite um aumento rápido e significativo de fármacos que não apresentam transporte transmembrana eficiente. Isso assume importância para a entrega de drogas polares, como bleomicina e cisplatina, que induzem alta citotoxicidade para células tumorais, quando são introduzidas em seus citoplasmas. Esse efeito é obtido mesmo se a concentração extracelular for baixa (TEISSIÉ et al., 2012).

A aplicação de campos elétricos sobre tecidos vivos não é recente. Em meados dos anos 1960, evidenciou-se que o emprego de diferenças de potencial da ordem de $25 \mathrm{kV}$ produziram alterações celulares irreversíveis em microrganismos, levando-os à morte (SALE; HAMILTON, 1967). Posteriormente, demostrou-se que a aplicação de $3,7 \mathrm{kV} / \mathrm{cm}$, em pulsos elétricos de $20 \mu \mathrm{s}$, cria poros em hemácias humanas causando a lise por permitir acesso ao citoplasma de substâncias, como íons, antes não permeáveis, ocasionando edema celular severo e rompimento citoplasmático (KINOSITA; TSONG, 1977).

A manutenção da viabilidade da célula após a eletroporação ocorre pela transitoriedade de poros formados na membrana citoplasmática (CIOBANU et al.,

\footnotetext{
${ }^{1}$ BRUNNER, Carlos Henrique Maciel. Eletroquimioterapia. In: DALECK, C.R.; De NARDI, A.B.; RODASKI, S. Oncologia em cães e gatos. 2 ed. São Paulo: Roca 2015. Cap.18. (Aceito para publicação em 2014). Pré-print.
} 
2007). A permeabilização fugaz da membrana celular por aplicação de pulsos elétricos de alto intensidade depende de diversos parâmetros físicos associados com a técnica, como: intensidade do pulso, número e duração (ROLS; TEISSIÉ, 1990).

A comparação da combinação de diversos tempos de duração de pulsos, variando de $20 \mu$ s até $1000 \mu \mathrm{s}$, com diferentes números de pulsos empregados, compreendendo a faixa de 1 a 64 pulsos elétricos na frequência de $1 \mathrm{~Hz}$, com amplitude de 40 a $600 \mathrm{~V}$, demonstrou que a técnica de 8 pulsos de $100 \mu \mathrm{sem} 1 \mathrm{~Hz}$ esteve presente entre os grupos mais eficientes in vitro, sendo que a de menor eficácia foi de 16 pulsos de 20 ss em frequência de $1 \mathrm{~Hz}$ (LEBAR et al., 2002).

Entre os primeiros trabalhos que evidenciaram a potencialização de efeitos citotóxicos de quimioterápicos pela aplicação de campos elétricos de alta intensidade destaca-se o de Okino e Mohri (1987) pelo pioneirismo. Porém a técnica preconizada foi de aplicação de pulsos elétricos de $5 \mathrm{kV} / \mathrm{cm}$ por $2 \mu \mathrm{s}$, sem que houvesse, na época, avaliação do tempo de permanência dos poros na membrana . Com o desenvolvimento da técnica de eletroporação in vivo a aplicação de oito pulsos de 100 us cada, em onda quadrada, em frequência de $1 \mathrm{~Hz}$, tem sido usada com preferência entre a maioria dos autores em estudos pré-clínicos e clínicos com eletroquimioterapia (MIR et al., 1991).

A despeito da definição do tipo de onda, sua duração e frequência entre os pulsos, a intensidade dos pulsos elétricos aplicados na técnica de eletroquimioterapia apresenta variação (SATKAUSKAS et al., 2005). A diferença de potencial elétrico pode ser de 500 a $1040 \mathrm{~V} / \mathrm{cm}$ (LEBAR et al., 2002) embora descrevam que abaixo de $800 \mathrm{~V} / \mathrm{cm}$ a poração da membrana citoplasmática seja reversível (GIARDINO et al., 2006). Diversos estudos pré-clínicos e clínicos em países como França, Itália, Eslovênia, Irlanda, Dinamarca foram realizados com a utilização da eletroquimioterapia (SERSA, 2006; SERSA et al., 2008b). Com base nesses trabalhos definiu-se critérios técnicos para procedimentos eletroquimioterápicos em humanos, projeto denominado ESOPE (European Standard Operating Procudeures of Electrochemothearpy), que fixa a diferença de potencial entre 1000 a 1300 V/cm (MIR et al., 2003).

$\mathrm{Na}$ década dos anos 1980 foram publicadas pesquisas com a utilização de pulsos elétricos de alta intensidade e com diferentes protocolos de duração e intensidade, utilizando ondas exponenciais ou quadradas (SERSA; CEMAZAR; 
RUDOLF, 2003). Posteriormente houve uso mais frequente de ondas quadradas, ou retangulares, para que a eletropermeabilização desejada fosse alcançada (NEUMANN; SCHAEFER-RIDDER, 1982; TOUNEKTI et al., 2001; MIR, 2006). Mais recentemente o protocolo envolvendo conjuntos de 8 pulsos de ondas retangulares, mas de aspecto bifásico, ou bipolar, tem sido adotado com sucesso (SPUGNINI; PORRELLO, 2003; SPUGNINI et al., 2007).

O protocolo padrão de EQT utiliza conjuntos de 8 pulsos com repetição na frequência de $1 \mathrm{~Hz}$, ou seja, 1 pulso por segundo. Nesse protocolo, o paciente humano relata sensação desagradável atribuída às contrações musculares provocadas pela despolarização das células em função da alta amplitude e baixa frequência dos pulsos elétricos (SHANKAYI; FIROOZABADI, 2011). Visando a redução desse desconforto, tem sido sugerido que a entrega de conjuntos de pulsos em uma frequência superior à capacidade de repolarização celular, como $5 \mathrm{kHz}$, transmite a sensação de um único pulso, minimizando então a dor (KITAMURA, 2003). Mesmo com redução do desconforto pelas várias contrações musculares, a variação entre as baixas frequências de $1 \mathrm{~Hz}$ ou os tratamentos com frequências altas de $5 \mathrm{kHz}$ não possuem diferenças entre os efeitos antitumorais (MIKLAVCIC et al., 2005).

Há certo consenso entre os pesquisadores que falta conhecimento a respeito do que realmente ocorre em nível molecular durante a eletropermeabilização da membrana citoplasmática. O tamanho exato dos poros formados pelo fenômeno de eletroporação não foi descrito com exatidão, porém por cálculos matemáticos podese estimar seu raio variando de 0,45 a $55 \mathrm{~nm}$ (DIMITROV; SOWERS, 1990).

Lipídios aparecem como alvo primário mas não único dos efeitos do campo elétrico, porém nas proteínas da membrana não foram observadas alterações diretas ou indiretas. Após os pulsos elétricos a permeabilização permanece por segundos, no período denominado de resealing que envolve dispêndio de energia celular. É bem aceito que a entrada de pequenas moléculas, como fármacos anticâncer, ocorre basicamente por processo de difusão após a poração (TEISSIÉ et al., 2012). A facilitação da penetração por meio eletroforético também pode ocorrer durante a duração de milissegundos dos pulsos elétricos (PUCIHAR et al., 2008).

O carregamento passivo durante um resealing lento permite um aumento rápido e significativo de fármacos que não apresentam transporte transmembrana eficiente. Isso assume importância para a entrega de drogas polares, como 
bleomicina e cisplatina, que induzem alta citotoxicidade para células tumorais, quando são introduzidas em seus citoplasmas. Esse efeito é obtido mesmo se a concentração extracelular for baixa (TEISSIÉ et al., 2012).

\subsection{BLEOMICINA}

Bleomicina é um antibiótico produzido por Streptomyces verticillatus de estrutura composta por glicopeptídeo solúvel em água e com peso molecular de 1500 daltons, apresenta citotoxicidade para células eucarióticas e é utilizado como quimioterápico no arsenal terapêutico oncológico (MIR; TOUNEKTI; ORLOWSKI, 1996).

Dependendo da presença ou não de oxigênio, a bleomicina atua sobre o DNA ocasionando de 8 a 10 pontos de quebra na molécula e portanto, é considerada uma microendonuclease (POVIRK; HAN; STEIGHNER, 1989). Os sítios de ação da bleomicina são as sequências GC e CT e em menor atividade sobre a sequência TA da molécula de DNA (D'ANDREA; HASELTINE, 1978).

A bleomicina é inativada pela bleomicina hidrolase, presente no interior das células animais, em local e de especificidade ainda não estabelecidos. A função de proteção das células contra a bleomicina por meio da bleomicina hidrolase é questionada (SEBTI et al., 1989).

Testes in vitro mostram que menos de $0,1 \%$ da bleomicina adicionada a um meio torna-se associada às células (ROY; HORWITZ, 1984). Embora tenha sido demonstrado que ocorre reconhecimento da bleomicina por uma proteína de membrana de $250 \mathrm{kDa}$ (TOUNEKTI et al., 1993), a membrana plasmática limita drasticamente o número de moléculas de bleomicina que entram no citoplasma celular (MIR; TOUNEKTI; ORLOWSKI, 1996), provavelmente pela natureza hidrofílica desse antibiótico citotóxico (PODDEVIN et al., 1991).

A bleomicina reage com proteínas específicas de superfície da membrana celular e se fixam a elas (PRON; BELEHRADEY JR; MIR, 1993); de fato a internalização desse quimioterápico ocorre por endocitose, se não houver 
eletroporação (MIR; ORLOWSKI, 1999; MUÑOZ MADERO; ORTEGA PÉREZ, 2011).

Uma vez que tenha alcançado o citoplasma celular, a bleomicina mantém-se no interior da célula por baixo transporte transmembrana (REED et al., 2010), atinge facilmente o núcleo através poros aquosos na membrana nuclear, realiza a quebra do DNA (PODDEVIN et al., 1991) e inibe a DNA ligase, enzima envolvida na reparação de danos ao DNA (GOOD; MILLER; HIGH, 2011).

Orlowski et al. (1988) demonstraram que a eletropermeabilização celular potencializa a citotoxicidade da bleomicina em 5 a 6 vezes de magnitude. Já MIR et al. (1991) relataram a potencialização desse fármaco in vivo em até 10.000 vezes. Algumas poucas centenas de moléculas que ganhem o citoplasma são necessárias para provocar a morte celular (PODDEVIN et al., 1991).

$\mathrm{Na}$ dependência da quantidade de moléculas internalizadas na célula, o mecanismo de morte celular se define entre apoptose, quando poucas moléculas de bleomicina atingem o citoplasma (TOUNEKTI et al., 1993), ou por mecanismo descrito como pseudoapoptose, se um grande número de moléculas atravessar a membrana citoplasmática (MIR; TOUNEKTI; ORLOWSKI, 1996).

A via de administração da bleomicina para eletroquimioterapia pode ser intralesional ou intravenosa, sendo a efetividade antitumoral por EQT similar para ambas (CEMAZAR et al., 2008). Para Mali et al. (2013a) a comparação das vias venosa e intralesional para EQT com bleomicina e cisplatina, demonstrou aumento significativo, na regressão completa tumoral, quando do uso da aplicação intralesional de bleomicina em contra ponto a via venosa. A baixa efetividade da EQT com bleomicina, aplicada por via venosa, pode ser explicada pelo volume insuficiente cobrindo com concentração adequada do fármaco todo o tumor, por força de fluxo sanguíneo heterogêneo ou por baixa concentração intersticial no momento da eletroporação (MALI et al., 2013b).

A citotoxicidade da bleomicina é tempo e concentração dependente (MIR; TOUNEKTI; ORLOWSKI, 1996). A janela de tempo após a aplicação do quimioterápico para a eletroporação recomendada pelo ESOPE é seguida na maioria dos estudos (MALI et al., 2013a).

Se a bleomicina for administrada por via intralesional, o volume tumoral deve ser mensurado para cálculo da dose empregada. Entre alguns métodos, pode-se 
medir 3 diâmetros ortogonais em mm (altura, $\mathrm{H}$; largura, $\mathrm{L}$ e comprimento, C) e aplicar na fórmula: 3,14 x H x L x C /6000 (SERSA; CEMAZAR; MIKLAVCIC, 2003).

\subsection{MECANISMO DE AÇÃO}

A morte celular induzida por dano na molécula de DNA inclui apoptose, um ativo processo de autodestruição, assim como morte em célula mitótica, que ocorre quando da passagem pela mitose de células contendo dano irreparável no DNA (COHEN-JONATHAN, 1999).

O exato mecanismo pela qual o dano ao DNA dispara o gatilho para a morte celular ainda está longe de ser perfeitamente conhecido, mas nesse contexto, a bleomicina mimetiza os efeitos da radioterapia (POVIRK; HAN; STEIGHNER, 1989).

Sob condições experimentais, a bleomicina atua sobre o DNA, causando quebra de fita simples ou de dupla fita, pelo mesmo mecanismo de ação, e desencadeando diferentes tipos de morte celular, dependendo do tipo e número de quebras do DNA. Em cultura de tecido, quantidades moderadas de bleomicina intracelular geram entre 500 e 50.000 quebras na dupla fita de DNA e induzem morte celular lenta, similar à morte celular mitótica por radiação ionizante. Por outro lado, quando quantidades maiores que $3 \times 10^{5}$ moléculas de bleomicina entram em cada célula, ocorre morte celular rápida por ação direta da bleomicina, sem ação relevante de endonuclease, com características, bioquímicas e morfológicas, de apoptose, fenômeno denominado como pseudoapoptose (TOUNEKTI et al., 1993).

\subsection{EFEITOS VASCULARES}

Além de facilitar a entrada de moléculas exógenas nos tecidos, a eletroporação atua modificando o fluxo sanguíneo nos tecidos tumorais e normais (BELLARD et al., 2012). Diferentes técnicas tem sido empregadas para avaliar as mudanças na circulação sanguínea após a eletroporação na eletroquimioterapia 
(CEMAZAR et al., 2008; JARM et al., 2010) e há significativa redução na perfusão local sem qualquer alteração no fluxo sanguíneo da circulação sistêmica (SERSA et al., 1999). A depuração do quimioterápico do tecido tumoral é impedida pela redução do fluxo sanguíneo (MIR et al., 2003), o que pode aumentar sua entrada em células tumorais permeabilizadas (BELLARD et al., 2012).

Em todas as áreas onde os pulsos elétricos são aplicados de maneira técnica adequada, as células acabam sendo eletroporadas, incluindo nesse fenômeno as células endoteliais dos vasos sanguíneos (SERSA; CEMAZAR; RUDOLF, 2003).

A eletroporação induz a duas fases transitórias que diminuem o fluxo sanguíneo no local da eletroporação. A primeira é imediata, intensa e muito fugaz, pois promove um bloqueio vascular de curta duração em decorrência de vasoconstricão arteriolar. A fase seguinte é mais lenta, de menor intensidade porém mais duradoura por comprometer a ultra estrutura vascular (JARM et al., 2010).

Foi demonstrado, mediante a pigmentação pelo azul patente, que o fluxo sanguíneo é recuperado totalmente com a eletroporação isolada após 24 horas. Quando da aplicação apenas de bleomicina não houve alteração no fluxo vascular. Porém quando houve a EQT com bleomicina, após $24 \mathrm{~h}$ da aplicação o fluxo sanguíneo no local foi virtualmente ausente (SERSA; CEMAZAR; MIKLAVCIC, 2003).

Após a aplicação isolada de 8 pulsos elétricos ocorre alteração vascular significativa, a partir de 1 hora dos pulsos e permanece por 24 horas após. O grau de redução do fluxo sanguíneo, sob $1040 \mathrm{~V}$, é dependente do número de pulsos aplicados, e menor efeito foi observado se menos que 8 pulsos forem aplicados. A perfusão sanguínea tumoral aumenta se o tecido for submetido a tensão entre 80 e $560 \mathrm{~V}$, e diminui sob amplitudes maiores que $640 \mathrm{~V}$ (SERSA et al., 1999).

Os efeitos vasculares mais precoces são associados à constrição de arteríolas e vênulas. A diminuição de diâmetro das vênulas é imediata após a eletroporação, dura aproximadamente 3 minutos, e é bem menos significativa que o efeito arteriolar, que também tem início imediato, é bem mais intenso que a constrição venular e dura aproximadamente 8 minutos até sua restauração completa ao diâmetro antes dos pulsos elétricos (BELLARD et al., 2012).

A causa da primeira fase da redução do fluxo sanguíneo, imediatamente após a aplicação dos pulsos elétricos, é ocasionada pela constrição reflexa das arteríolas por estímulo local do sistema nervoso simpático. Esse mecanismo foi comprovado 
pelo uso experimental de reserpina, droga que depleta as terminações nervosas de norepinefrina. Desse modo, animais que recebiam previamente esse fármaco não sofriam redução do fluxo sanguíneo imediatamente após a eletroporação (GEHL; SKOVSGAARD; MIR, 2002). É importante que se ressalte que esse efeito vascular, sem associação com quimioterápicos, não tem efeito antitumoral (JARM et al., 2010).

Minutos após a redução do fluxo sanguíneo por vasoconstricão, em decorrência da aplicação de pulsos elétricos, ainda ocorre baixa perfusão do tecido eletroporado que assim permanece por, ao menos, 30 minutos. Esse fenômeno ocorre por eletroporação de fibras musculares e células endoteliais, e com isso ocorre aumento da pressão intersticial e diminuição da pressão intravascular (GEHL; SKOVSGAARD; MIR, 2002).

Mesmo após o efeito vascular inicial por eletroporação, é possível se evidenciar decréscimo significativo no fluxo sanguíneo por danos causados nas células endoteliais da neoplasia (CEMAZAR et al., 2008).

Tem sido demonstrado que as células endoteliais dos capilares sanguíneos são expostas a um campo elétrico $40 \%$ maior que as células tumorais circunvizinhas, tornando-as mais susceptíveis às alterações promovidas pela EQT (SERSA et al., 2008a). Os pulsos elétricos promovem desarranjo de microfilamentos e microtúbulos do citoesqueleto das células endoteliais (MEULENBERG; TODOROVIC; CEMAZAR, 2012), tornando-as aumentadas e arredondadas, comprometendo a função de barreira do endotélio vascular, e aumentando a resistência ao fluxo sanguíneo (JARM et al., 2010).

O bloqueio vascular provocado pela vasoconstrição reflexa após a eletroporação, faz com que ocorra represamento sanguíneo local e consequentemente, aumento do tempo em que as células tumorais ficam expostas aos quimioterápicos, prevenindo também sangramento nos tecidos (JARM et al., 2010; TESTORI et al., 2010). Esse período é mais pronunciado nos tecidos neoplásicos, provavelmente secundário ao tipo de vascularização tumoral que se apresenta de forma irregular, e por isso pode permanecer por horas, ao contrário de poucos minutos nos tecidos normais (MIR et al., 2003). A vascularização tumoral tende a ser caótica e inadequadamente desenvolvida, além do fato dos vasos sanguíneos serem estruturalmente e funcionalmente anormais, como consequência o fluxo de sangue da microcirculação é inferior ao do tecido normal, contribuindo 
para um estado de hipóxia tecidual. Observa-se também permeabilidade alterada das paredes dos capilares tumorais, decorrentes de anormalidades na membrana basal e no próprio revestimento endotelial, permitindo que grandes moléculas passem através delas. O aumento de extravasamento associado à inadequada drenagem linfática, faz com que se eleve a pressão no interstício do tumor, prejudicando ainda mais a circulação local. Nesse contexto, os tumores são bastante atrativos para terapias com alvos vasculares e a técnica de eletroquimioterapia também explora essa particularidade da vascularização tumoral (JARM et al., 2010).

\subsection{RESVERATROL}

O resveratrol $(3,5,4$ ' -trihydroxystilbene) é uma fitoalexina contida em uma variedade de plantas como uvas, amendoim e mirtilo (blueberry). A molécula existe sob a forma de dois isômeros: cis e trans (CAMONT, 2009).

Estudos tem demonstrado que o resveratrol possui atividade antioxidativa e anti-inflamatória, assim como efeito cardioprotetor e redução dos efeitos da idade em ratos (HAN, 2015). O mecanismo de ação da substância não é completamente conhecido, porém parte de sua atividade relaciona-se a ativação da sirtuina 1 (GERTZ et al., 2010). As sirtuinas integram um grupo de deacetilases dependentes de NAD, o que as vincula ao metabolismo celular, relacionando-se ao silenciamento gênico, a morte celular, longevidade, inflamação e câncer (HOUTKOOPER et al., 2012). De particular interesse no âmbito da biologia tumoral é a modulação pelas sirtuinas da atividade dos fatores transcricionais HIF-1 $\alpha$ e NFkB, diretamente relacionados à progressão tumoral (TAFANI et al., 2013). Um evento central relacionado a atividade de HIF-1 $\alpha$ é a mediação do processo de neovascularização tumoral (BRANCO-PRICE et al., 2012). Nesse sentido, a modulação da expressão desses fatores pode representar uma importante alternativa terapêutica no tratamento de pacientes oncológicos.

Mesmo com a promissora eficácia do resveratrol em inibir e suprimir o crescimento tumoral em vários estudos in vitro, o exato mecanismo do efeito antiproliferativo ainda continua sendo investigado. A literatura sugere que no câncer 
o resveratrol segundo múltiplos mecanismos como: indutor de apoptose, antiproliferativo, anti-inflamatório e antangiogênico (NWACHUKWU et al., 2014). Ainda não está claro se os efeitos anti proliferativos do resveratrol sobre as células tumorais são devido as efeitos diretos sobre as células tumorais ou efeitos indiretos sobre a angiogênese (SINGH, NDIAYE, 2014).

Sirtuinas são diacetilases ligadas ao metabolismo do NAD+, portanto participam da atividade de níveis de energia celular (KULKARNI; CANTÓ, 2014). Sirtuinas são envolvidas na regulação do metabolismo, resposta ao stress, e aparentemente se relaciona ao aumento da longevidade (DANG, 2014). Os mamíferos possuem 7 isoformas de sirtuinas. As Sirt 1, Sirt 6 e Sirt 7 são principalmente nucleares, sendo que a Sirt 1 e Sirt 6 com fortes evidencias de relação com o envelhecimento. Três sirtuinas, a Sirt 3, Sirt 4 e Sirt 5 estão localizadas em mitocôndrias, sendo a Sirt 3 ligada ao envelhecimento e regula enzimas do metabolismo energético. A Sirt 5 é fortemente expressa em linfoblastos e relacionada a doenças malignas e ao metabolismo da ureia. $\mathrm{O}$ ativador de sirtuina mais seletivo de isoforma é o resveratrol, que nos mamíferos estimula Sirt 1 (GERTZ, 2010).

\subsection{HIF $1 \alpha$}

Os organismos respondem rapidamente a mudanças na disponibilidade de oxigênio. Essas respostas são desencadeadas por muitos sistemas sensíveis ao oxigênio, localizados em diferentes níveis do organismo, ativando redes complexas de sinalização que culminam com o controle de expressão gênica. As vias de sinalização ativadas por baixa disponibilidade de oxigênio, permitem à célula a adaptação e sobrevivência ao microambiente com hipóxia (BENIZRI et al., 2008).

Proliferação acelerada e ou retardo na apoptose, fundamentais para o crescimento tumoral, resultam em regiões de hipóxia crônica. A hipóxia tumoral é um fator para se estabelecer prognóstico e tem sido relacionada a tumores de crescimento agressivo, metastáticos e de pouca respostas às terapias (HÖCKEL et al, 1993). O papel da hipóxia na regulação da expressão dos genes é de potencial 
importância para o entendimento desses efeitos (HANAHAN; FOLKMAN, 1996). Estudos de expressão genética tem encontrado várias classes de genes que são supra regulados em regiões de hipóxia tumoral, e demonstram que a ativação do complexo transcricional Fator Induzido por Hipóxia 1(HIF-1) é o mediador central de muitos desses efeitos (CARMELIET; COLLEN, 1998; CARMELIET; MOONS; COLLEN, 1998).

Estudos com o gene de eritropoietina induzido por hipóxia identificaram uma sequencia do DNA chamada de eritropoietina 3' potencializadora. Análise desses genes encontraram sequencias de controle similar entre a eritropoietina e a eritropoietina 3' potencializadora, denominados então como Elementos de Resposta à Hipóxia (HREs). A análise detalhada da eritropoietina 3' potencializadora levou à definição do HIF-1, como um complexo ligante ao DNA que é crítico para a função dessa sequencia. $O$ complexo ligante tem mostrado ser uma proteína heterodimérica de dupla hélice PAS denominada HIF- $\alpha$ e HIF- $\beta$ (WANG et al., 1995). O HIF $\alpha$ é classificado em três isoformas: HIF1- $\alpha$, HIF2- $\alpha \square$ e HIF3- $\alpha$ sendo o HIF1- $\alpha$ a subunidade mais estudada (CUMMINS; TAYLOR, 2005). A ativação do complexo transcricional HIF contribui de maneira significante às respostas adaptativas à hipóxia e se constitui em um dos principais reguladores da homeostasia do oxigênio (BENIZRI; GINOUVÈS; BERRA, 2008).

A regulação $\mathrm{O}_{2}$-dependente do $\mathrm{HIF} \alpha$ é essencialmente pós-transcricional e envolve tanto a regulação da estabilidade quanto a de sua atividade por um mecanismo que é $\mathrm{O}_{2}$-dependente: a hidroxilação da prolina e resíduos de asparagina (KE; COSTA, 2006).

Em células bem oxigenadas, HIF é uma proteína de vida excepcionalmente curta, com meia vida inferior a 5 minutos, e seu nível básico é muito baixo. Porém quando da disponibilidade reduzida de $\mathrm{O}_{2}, 0 \mathrm{HIF}$ tem seus níveis elevados por relaxamento de sua degradação ubiquitina-proteassoma (KOSHIJI; HUANG, 2004).

A ubiquitina é uma proteína que tem função relevante na regulação das proteínas intracelulares, por marcar proteínas indesejadas para que sejam degradadas por organelas chamadas proteassomas. A via da ubiquitinaproteassoma é uma via proteolítica que se difere das demais devido a seu consumo de ATP. A via se inicia com a ubiquitinação da proteína alvo, havendo cinco alvos principais da ubiquitina: receptores da membrana celular, moduladores de 
crescimento e supressores de tumor, ativadores e inibidores de transcrição, reguladores do ciclo celular e por fim, proteínas mutantes ou danificadas. A ubiquitinação de uma proteína ocorre em etapas e envolve 3 enzimas, chamadas de E1 (enzima ativadora da ubiquitina), E2 (enzima conjugadora) e E3 (ubiquitina ligase). O processo consome 1 ATP para a ativação de cada molécula de ubiquitina e também no desdobramento da proteína realizado pelo proteassoma que fragmenta a proteina mais ubiquitina em peptídeos de 7 a 9 aminoácidos (CIECHANOVER, 1998).

A degradação do HIF $\alpha$, via ubiquitina-proteassoma, necessita do pVHL, produto do gene supressor do tumor von Hippel-Lindau, que possui ação de ubiquitina E3 ligase. A hidroxilação de dois resíduos de prolina (Pro402 e Pro564), contidos no domínio de degradação oxigênio dependente (ODDD), aciona a ligação do pVHL ao HIF $\alpha$ e proteassoma (MAXWELL et al., 1999).

A estabilização HIF $\alpha$ é devido ao rompimento da interação pVHL/HIF $\alpha$ sob condições de hipóxia. Dois grupos independentes de enzimas foram identificados catalizando as reações de hidroxilação: HIF prolil hidrolase e prolil hidrolase de domínio contendo proteína, denominadas como PHDs (BRUICK; MCKNIGHT, 2001). Essas enzimas necessitam de $\mathrm{O}_{2}$ como co-substrato e funcionam como a base molecular da função de sensores de $\mathrm{O}_{2}$ (HIRSILÄ et al., 2003).

Em humanos e em camundongos foram identificados três genes PHDs, phd1, phd2 e phd3 (BRUICK; MCKNIGHT, 2001). A localização das três isoformas é variável: PHD1 aparece exclusivamente no núcleo, PHD2 principalmente no citoplasma e PHD3 em ambos os compartimentos celulares (METZEN et al., 2003). A contribuição de cada PHD na regulação do HIF $\alpha$ é dependente de sua concentração; o que se observa é que PHD1 e PHD3 contribuem para a regulação de HIF $\alpha$ apenas sob hipoxia crônica e PHD2 é de concentracão autolimitante em normoxia (BERRA et al., 2003). Entretanto, a expressão dos PHDs é fortemente regulada tanto em nível transcricional quanto pós trancricional (SEMENZA, 2003).

Inicialmente identificado como o regulador da expressão gênica da eritropoitina, foi demonstrado que o HIF controla muitos genes hipóxia-alvo (BERRA et al., 2003). Na verdade, promovendo a transcrição de todos esses genes, o HIF ajuda manter a homeostase $\mathrm{O}_{2}$ (BENIZRI; GINOUVÈS; BERRA, 2008). 


\subsection{FATOR VIII ANTÍGENO RELACIONADO}

O fator VIII antígeno relacionado, ou fator de Von Willebrand (VWF), é uma glicoproteína multimérica que media a agregação plaquetária ao subendotélio de sítios com injúria vascular (RUGGERI, 1993) combinando receptores específicos de membrana de plaquetas, glicoproteína lb e glicoproteína Ilb/IIla, com constituintes do tecido conectivo subendotelial , assim como estabiliza o fator VIII, uma proteína procoagulante no sangue, ligando-se a ela e retardando sua degradação (YAMAMOTO et al., 1998). O vWF é sintetizado a partir de um mRNA de 8,7 kDa e aparentemente é expresso exclusivamente em células endoteliais e megacariócitos, que apresentam um padrão granular de reatividade por ser estocado nos corpúsculos de Weibel-Palade (WARHOL; SWEET, 1984). Marcadores de células endoteliais são usados para se identificar essas células, e o vWF é um dos marcadores mais utilizados (MIDDLETON et al., 2005).

\subsection{VEGF}

O conceito de que o crescimento tumoral é dependente de angiogênese foi estabelecido pela primeira vez por Folkman tendo como base que, uma vez o tumor tenha se formado, cada aumento na população celular tumoral deve ser precedido por um aumento no número de capilares neoformados que convergem ao tumor. Evidentemente esse conceito hipotético é genérico e merece qualificações, pois células tumorais crescem sob a forma ascítica sem neovascularização, assim como em estágios muito iniciais de tumores, como carcinomas in situ, a população tumoral pode ser tão pequena que pode não necessitar de angiogênese (FOLKMAN, 1990). Em sentido oposto, estudos posteriores utilizando camundongos transgênicos como modelos experimentais, comprovaram que a angiogênese pode inclusive ocorrer em um estágio pré-neoplásico (HANAHAN; FOLKMAN, 1996). Nas últimas décadas um grande número de fatores angiogênicos foram identificados como indutores, diretos ou indiretos, de proliferação e diferenciação de células endoteliais. Desses, o 
polipeptídeo Fator do Crescimento Endotelial Vascular A (VEGF-A) é o principal regulador de angiogênese fisiológica e patológica atuando como chave reguladora da angiogênese tumoral (BAERISWYL; CHRISTOFORI, 2009).

O VEGF-A faz parte da família dos genes que codificam o Fator de Crescimento Plaquetário (PIGF), VEGF-B, VEGF- C, VEGF-D e VEGF-E, que possuem afinidade aos receptores tirosina quinase VEGFR-1, VEGFR-2 e VEGFR-3 (FERRARA; GERBER; LECOUTER, 2003). Enquanto o VEGF-A se liga ao VEGFR2 nas células endoteliais do vasos sanguíneos promovendo angiogênese vascular sanguinea, o VEGF- C e VEGF-D preferencialmente se ligam ao VEGFR-3 expressado de forma mais consistente em vasos linfáticos, promovendo assim a linfoangiogênese. O VEGF-A possui isoformas que se combinam com alta afinidade ao VEGFR-1 e VEGFR-2. As apresentações VEGF-A145, 165, 189 e 206 são heparina ligantes e requerem ação enzimática da superfície da célula e da matriz extracelular para exercerem suas atividades angiogênicas. O VEGF-A121 é distribuído livremente e não necessita ativação (TISCHER et al., 1991; POLTORAK et al., 1997).

O VEGFA está envolvido na orquestração do crescimento de novos vasos sanguíneos durantes a embriogênese e desenvolvimento pós-natal. Sendo que a expressão gênica pode ser supra regulada por hipóxia e por sinalização de oncogenes (HANAHAN; WEINBERG, 2011).

\subsection{OBJETIVOS}

Avaliar a eficácia da eletroquimioterapia com bleomicina sobre o crescimento do tumor de Erlich na forma sólida;

Avaliar qualitativa e quantitativamente os efeitos de quimioterapia com bleomicina, da eletroporação e da eletroquimioterapia com bleomicina sobre a vasculatura do tumor de Ehrlich;

Avaliar os efeitos do resveratrol, associado ou não à eletroquimoterapia, sobre a vascularização do tumor de Ehrlich. 


\section{AVALIAÇÃO DA VASCULATURA DO TUMOR DE EHRLICH NA FORMA SÓLIDA EM CAMUNDONGOS TRATADOS COM ELETROQUIMIOTERAPIA COM BLEOMICINA}

RESUMO

A eletroquimioterapia é uma modalidade de tratamento que combina a eletroporação e a quimioterapia, apresentando efeito superior ao dos procedimentos em separado, utilizada no tratamento de neoplasmas superficiais, apresentando bons resultados terapêuticos a despeito da histogênese tumoral. No entanto a compreensão do processo ainda é parcial, em particular no que tange à microarquitetura tumoral após o tratamento. No presente estudo buscou-se uma maior compreensão desses eventos avaliando-se qualitativa e quantitativamente, com auxílio da imunomarcação, a vasculatura tumoral de camundongos portadores do tumor de Ehrlich na forma sólida em animais não tratados e camundongos submetidos à quimioterapia e eletroquimioterapia, em paralelo à avaliação do crescimento tumoral. Identificou-se redução do volume tumoral em animais submetidos à eletroquimioterapia com bleomicina, e efeito oposto em camundongos tratados apenas com bleomicina. Evidenciou-se maior densidade microvascular tumoral em animais tratados com quimioterapia, quando comparados aos não-tratados e aos submetidos à eletroquimioterapia $(p<0,001)$. Os tratamentos empregados, quimioterapia e eletroquimioterapia, apresentaram efeitos antagônicos sobre 0 crescimento tumoral, possivelmente em razão de sua ação, respectivamente, aumentando e reduzindo a vasculatura tumoral.

Palavras-chave: Oncologia experimental. Eletroquimioterapia. Vascularização neoplásica. Fator VIII. 


\subsection{REVISÃO DE LITERATURA}

A eletroquimioterapia é uma modalidade de terapia oncológica que, por meio da aplicação de pulsos elétricos de parâmetros definidos, torna as membranas celulares transitoriamente permeáveis, facilitando o ingresso de moléculas pouco absorvíveis, como a bleomicina, um potente quimioterápico com penetração celular in vitro abaixo de 0,1\% (ROY; HORWITZ, 1984). Mediante a eletroporação, no entanto, a bleomicina entra livremente na célula (MIR et al., 2006), antagonizando o crescimento tumoral particularmente por via apoptótica (TOUNEKTI et al., 1993). Devido a sua baixa permeabilidade celular, a bleomicina é um quimioterápico com efeitos adversos mínimos (MIR; TOUNEKTI; ORLOWSKI, 1996).

Um evento paralelo induzido pela aplicação de pulsos elétricos é uma severa redução no fluxo sanguíneo local. Por um período fugaz os pulsos reduzem a perfusão tumoral, por meio de estímulo ao sistema nervoso simpático, efeito que se prolonga em razão do desarranjo em microfilamentos e microtúbulos do citoesqueleto das células endoteliais induzido pelo procedimento (MEULENBERG; TODOROVIC; CEMAZAR, 2012). Por outro lado, a aplicação apenas de bleomicina não promove alteração no fluxo vascular (SERSA; CEMAZAR; MIKLAVCIC, 2003). Comparativamente, o retorno à perfusão original ocorre em poucas horas em tecidos hígidos em relação ao tecido neoplásico (SERSA et al., 2002). Vários estudos indicam a elevada atividade antitumoral da eletroquimioterapia em fibrossarcomas, melanomas e carcinomas em camundongos, ratos e coelhos, com bons resultados clínicos em felinos, caninos, equinos e quelônios (SERSA et al., 1996; MARTY et al., 2006; SERSA; MIKLAVCIC, 2008; SILVEIRA; BRUNNER; FUTEMA, 2010; BRUNNER et al., 2014). Particularmente em camundongos refere-se elevado percentual de cura em animais portadores do tumor de Ehrlich (SERSA et al., 1996).

O fator VIII antígeno relacionado, ou fator de Von Willebrand (vWF), é uma glicoproteína que media a agregação plaquetária ao subendotélio de sítios com injúria vascular (RUGGERI, 1993) combinando receptores específicos de membrana de plaquetas, glicoproteína lb e glicoproteína Ilb/llla, com constituintes do tecido conectivo subendotelial (YAMAMOTO et al., 1998). O fator VIII antígeno relacionado é aparentemente expresso exclusivamente em células endoteliais e megacariócitos (WARHOL; SWEET, 1984). Como marcador de células endoteliais o fator VIII 
antígeno relacionado é um dos mais utilizados (MIDDLETON et al., 2005). A marcação por meio de anticorpos monoclonais contra o fator VIII pode ser aplicada em tecidos fixados em formol sendo utilizada para coloração de vasos e identificação das áreas tumorais de maior vascularização (RUITER et al., 1989).

No presente estudo busca-se uma maior compreensão desses eventos avaliandose qualitativa e quantitativamente, com auxílio da imunomarcação com fator VIII, a vasculatura tumoral de camundongos portadores do tumor de Ehrlich na forma sólida em animais não-tratados e em camundongos submetidos à quimioterapia e eletroquimioterapia com bleomicina.

\subsection{MATERIAL E MÉTODO}

\subsubsection{Animais}

Foram utilizados 40 camundongos BALB-c, fêmeas, pesando entre 25 e $30 \mathrm{~g}$, mantidos no Biotério da Universidade Paulista sob ciclo invertido, com condições de iluminação controlada, temperatura mantida entre $20^{\circ}$ e $25^{\circ} \mathrm{C}$ e umidade relativa do ar entre 55 a 65\%, recebendo ração ${ }^{2}$ e água ad libitum.

\subsubsection{Tumor de Ehrlich}

Os animais receberam suspensão subcutânea, na região lombar dorsal, de $0,1 \mathrm{ml}$ contendo $5,0 \times 10^{6}$ células do tumor de Ehrlich, sendo aleatoriamente divididos em grupos controle $(C)$; quimioterapia $(Q)$ e eletroquimioterapia $(E)$.

\footnotetext{
${ }^{2}$ Biobase $9310 \mathrm{~A} \AA$ - Biobase Nutrição Animal, Aguas Claras, SP
} 


\subsubsection{Tratamento}

Foi realizado aproximadamente 30 dias após inoculação tumoral procedendose, inicialmente aos tratamentos, o cálculo do volume tumoral pela mensuração dos maiores diâmetros com paquímetro, aplicando-se a fórmula: $V=L . E . P . \pi: 6000$, sendo V=volume; L=largura; $E=$ =spessura; $P=$ profundidade .

\subsubsection{Quimioterapia}

Os animais submetidos à quimioterapia receberam bleomicina ${ }^{3}$ por via intralesional na dose de $1 \mathrm{U}$ por $\mathrm{cm}^{3}$ de tumor.

\subsubsection{Eletroquimioterapia}

Os camundongos submetidos à eletroquimioterapia foram anestesiados, com associação de quetamina ${ }^{4}$, xilazina ${ }^{5}$ e morfina ${ }^{6}$, na dose de 2,5 mg, 1,0 mg e 0,3 mg respectivamente, para cada $100 \mathrm{~g}$ de animal, por via intraperitoneal, recebendo bleomicina por via intralesional na dose de $1 \mathrm{U}$ por $\mathrm{cm}^{3}$ e imediatamente após, sequências de oito pulsos elétricos de 100 us cada, em onda quadrada monopolar de $1000 \mathrm{~V} / \mathrm{cm}$, com frequência de $1 \mathrm{~Hz}$, através de gerador de pulsos ${ }^{7}$ (BRUNNER, 2009).

\footnotetext{
${ }^{3}$ Cinaleo®- Meizler UCB Biopharma SA, Barueri, SP

${ }^{4}$ Dopalen ${ }^{\circledR}$ - Vetbrands Produtos Farmacêuticos, Paulinia - SP

${ }^{5}$ Xilazin $\AA^{\circledR}$-Syntec Produtos Farmacêuticos, Cotia - SP

${ }^{6}$ Dimorf® - Cristalia Produtos Químicos Farmacêuticos, Itapira, SP

${ }^{7}$ BK 100® LC Pesquisa ME, São Paulo, SP
} 


\subsubsection{Avaliação macroscópica}

Após 7 dias dos tratamentos foi realizada a eutanásia com isofluorano dos animais. Foram colhidos fragmentos de pele da região inoculada com o tumor que teve seu volume tumoral calculado. A evolução tumoral no período foi calculada dividindo-se volume tumoral final (Vf) pelo volume tumoral inicial (Vi). O percentual de crescimento ou remissão pela fórmula: $((\mathrm{Vf} / \mathrm{Vi})-1)^{\star} 100$.

\subsubsection{Avaliação histológica}

Após a avaliação macroscópica o tecido tumoral foi submetido à fixação em solução de formol a 10\%, seguindo-se processamento histológico de rotina, corando-se os cortes pela hematoxilina/eosina.

\subsubsection{Procedimento imuno-histoquímico}

Para a imunomarcação seguiu-se a metodologia descrita (HSU; RAINE; FANGER, 1981). Cortes histológicos de $4 \mu \mathrm{m}$ foram dispostos em lâminas e submetidos à recuperação antigênica pelo calor em panela de pressão, contendo solução tampão de citrato de sódio a 0,01M, pH 6,5, por 5 minutos em ebulição. Após resfriamento da solução foi realizada lavagem das lâminas em PBS. O procedimento seguinte foi o bloqueio da peroxidase endógena através da incubação por 30 minutos em solução contendo $80 \%$ de álcool metílico e $20 \%$ de peróxido de hidrogênio 30 volumes, seguindo-se lavagem das lâminas por 3 vezes em PBS. A etapa seguinte foi a incubação com o anticorpo primário, utilizando-se anticorpo policlonal de coelho anti-humano para fator VIII, clone A0082, DAKO, na diluição de 1:400, em solução composta por $0,5 \mathrm{ml}$ de azida sódica a $5 \%, 0,25 \mathrm{ml}$ de albumina bovina fração $V$ (Sigma) a $5 \%$ e $12 \mathrm{ml}$ de PBS. As lâminas permaneceram em câmara úmida por $12 \mathrm{~h}$ a $4^{\circ} \mathrm{C}$. Seguiu-se a incubação com anticorpo secundário e 
complexo estreptavidina-peroxidase (LSAB,DAKO). Para a revelação foi empregada solução contendo cromógeno diaminobenzidina em $20 \mathrm{ml}$ de PBS e mantida em freezer a $20^{\circ} \mathrm{C}$. Antes da utilização foi acrescentado $5 \mathrm{ml}$ de peróxido de hidrogênio 30 volumes para cada $2 \mathrm{ml}$ da solução cromógena, aplicando-se sobre a lâmina deixando reagir por 1 minuto. Foi realizada a lavagem em água destilada, contracorando-se pela hematoxilina, seguindo-se desidratação, diafanização e montagem em resina sintética e lamínula.

\subsubsection{Morfometria vascular}

A vascularização foi quantificada contando-se estruturas vasculares, positivas para fator VIII, em 10 campos de grande aumento de cada grupo. Foram evitadas áreas francamente necróticas e territórios periféricos, limítrofes ao crescimento neoplásico. Os campos foram capturados por câmera ${ }^{8}$ acoplada ao microscópio ${ }^{9}$, realizando-se a contagem de vasos em cada um deles, calculando-se em sequência a média, desvio padrão e erro padrão para cada grupo.

\subsection{Análise estatística}

Os resultados obtidos na mensuração do volume tumoral e a quantificação vascular foram analisados pela metodologia ANOVA seguida do teste de TukeyKramer

\footnotetext{
${ }^{8}$ Motic ${ }^{\circledR}$ Motic Asia, Caseway Bay, Hong Kong

${ }^{9}$ Nikon E200 ${ }^{\circledR}$ Nikon do Brasil Ltda, São Paulo, SP
} 


\subsection{RESULTADOS}

O peso dos camundongos foi mantido ou sofreu ganho em todos os animais testados no período de 7 dias entre os tratamentos (Tabela 1). O padrão de crescimento tumoral foi heterogêneo, observando-se, após período semelhante de desenvolvimento ampla variação de dimensões.

Todos os animais submetidos à EQT apresentaram redução no volume tumoral identificando-se evolução oposta nos camundongos tratados isoladamente com quimioterapia (Gráfico 1), com diferença estatisticamente significante entre os animais controle e os tratados com eletroquimioterapia (Tabela 2).

Tabela 1 - Evolução do peso dos camundongos BALB-c durante 7 dias de experimentação

\begin{tabular}{lccc}
\hline Grupo & $\begin{array}{c}\text { Média de ganho de } \\
\text { peso }\end{array}$ & Desvio padrão & Erro padrão \\
\hline SHAM & 1,55 & 1,90 & 0,85 \\
Controle & 1,28 & 1,29 & 0,57 \\
quimioterapia & 0,60 & 0,40 & 0,20 \\
eletroquimioterapia & 1,26 & 0,57 & 0,28
\end{tabular}

Diferenças estatisticamente não significantes com $p>0,05$ entre os grupos (ANOVA/Tukey-Kramer).

Tabela 2 - Evolução tumoral dos camundongo BALB-c com tumor de Ehrlich em forma sólida após 7 dias de experimentação

\begin{tabular}{lcccc}
\hline Grupo & $\begin{array}{c}\text { Média de evolução } \\
\text { volume tumoral (Vf/Vi) }\end{array}$ & Desvio padrão & Erro padrão \\
& 4,97 & $\pm 4,17$ & \\
\hline Controle & 3,75 & $\pm 4,06$ & $\pm 1,86$ \\
Quimioterapia & $0,55^{\star}$ & $\pm 0,30$ & $\pm 2,03$ \\
Eletroquimioterapia & & $\pm 0,15$
\end{tabular}

*Diferença estatisticamente significante com $p<0,05$ entre os grupos controle e eletroquimioterapia (ANOVA/Kruskal-Wallis).Vf, volume final; Vi, volume inicial.

Histologicamente, no entanto, não foram identificadas alterações relativas às características tumorais, evidenciando-se em todos os casos neoplasmas altamente anaplásicos, com crescimento sólido e invasão de estruturas adjacentes, 
associando-se amplas áreas de necrose tecidual (Figura 1). Também não foram evidenciadas diferenças na morfologia vascular tumoral nos diferentes grupos.

Figura 4 - Fotomicrografia de corte histológico do tumor de Ehrlich

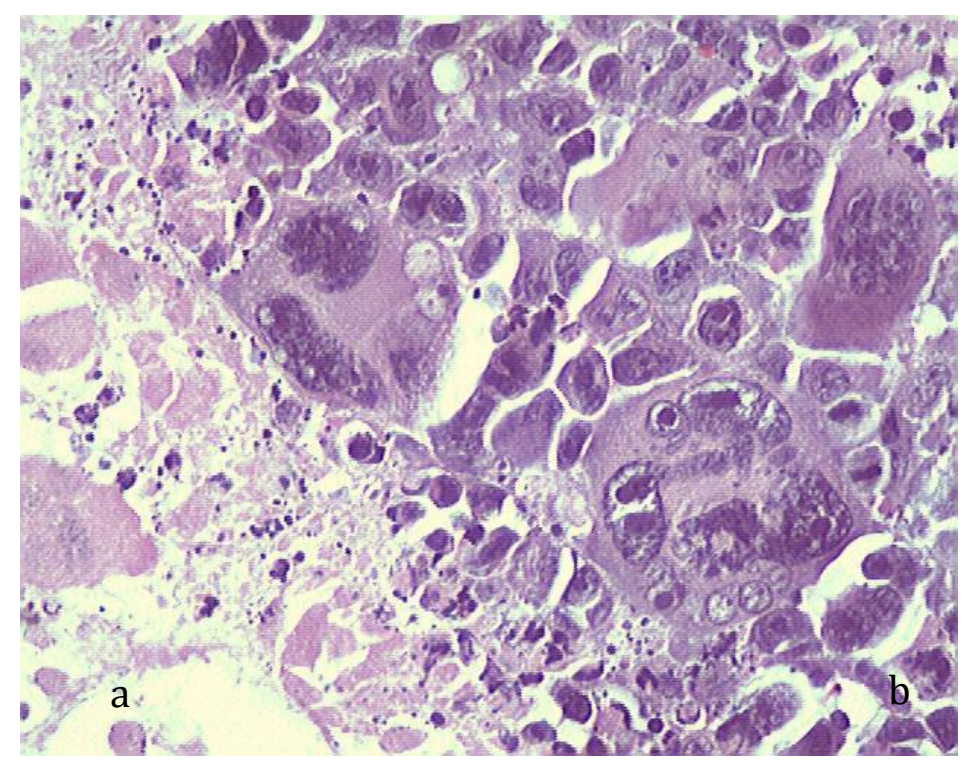

Fonte: XAVIER, J.G.

Legenda: Extensa necrose (a) e células carcinomatosas (b), hematoxilina-eosina, obj. 40x

Gráfico 1 - Evolução tumoral no período de 7 dias em camundongos BAB-c portadores de tumor de Ehrlich na forma sólida sem tratamento, tratados com quimioterapia ou tratados com eletroquimioterapia

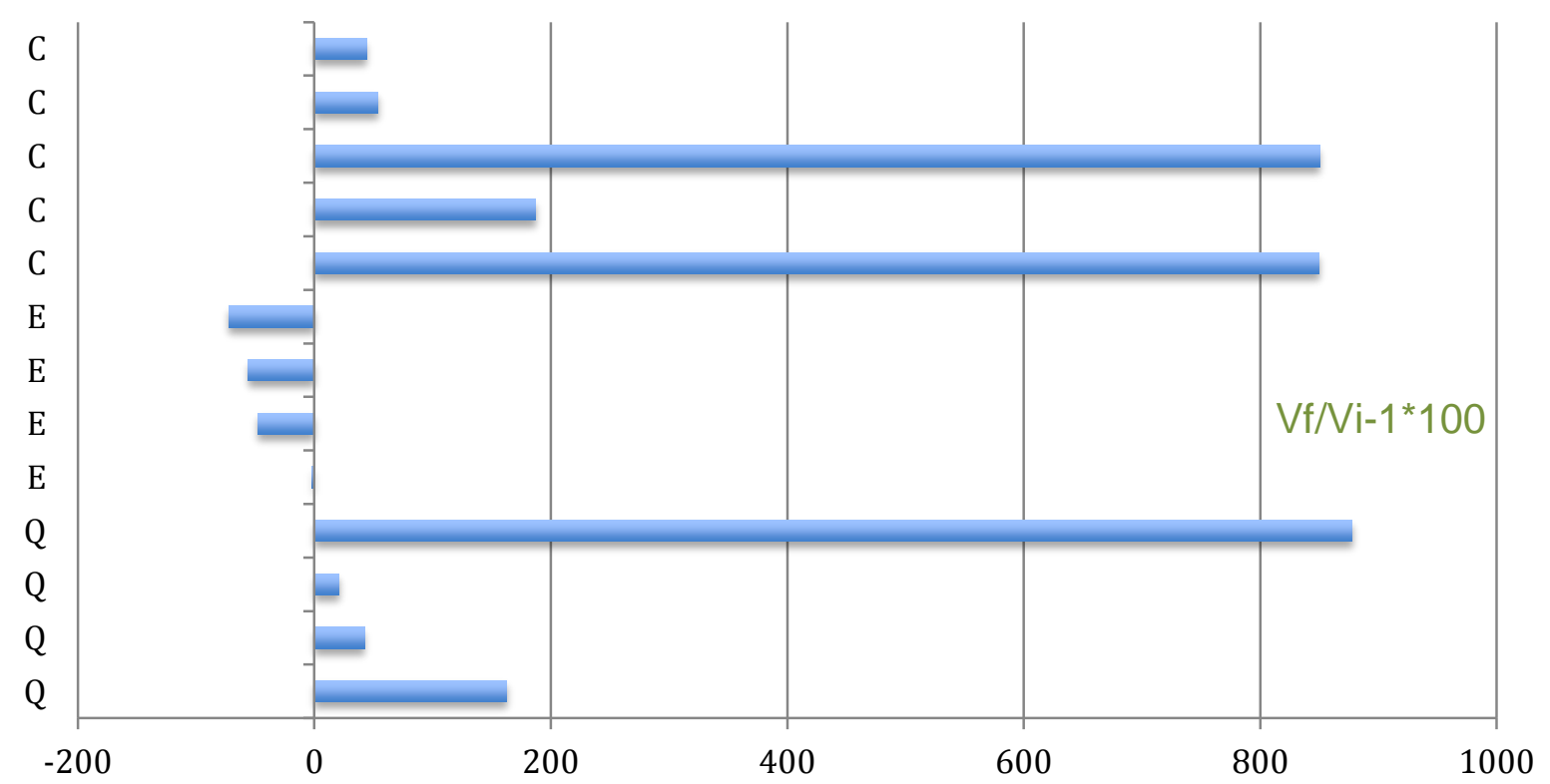

Legenda: C, controle; $Q$, quimioterapia. E, eletroquimioterapia; Vf volume tumoral final, Vi volume tumoral inicial. 
A imunopositividade ao fator VIII foi observada em todas as amostras (Figura 2), com tendência à vascularização decrescente, considerando-se os grupos quimioterapia, controle e EQT (Gráfico 2), evidenciando-se diferença estatisticamente entre a densidade microvascular comparando-se os grupos controle $x$ quimioterapia e quimioterapia $x$ eletroquimioterapia, com $p<0,001$ em ambos os casos (Tabela 3).

Figura 5 - Fotomicrografia de corte histológico de tumor de Ehrlich sólido em animal submetido à quimioterapia com bleomicina

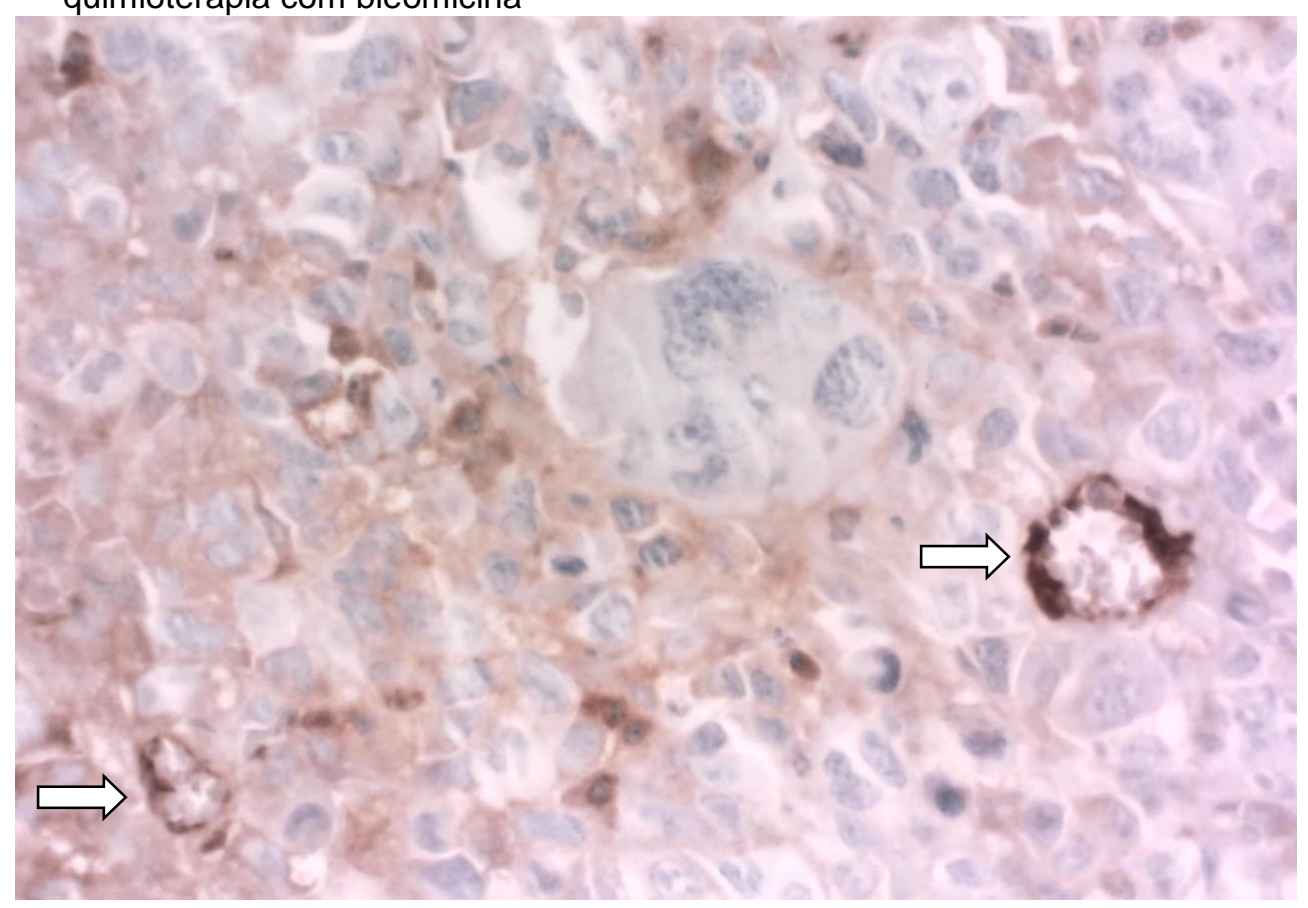

Fonte: XAVIER, J.G.

Legenda: Imunopositividade endotelial ao fator VIII (setas), Estreptavidina-biotina-peroxidase, obj. 40x

Tabela 3 - Densidade microvascular tumoral em animais portadores do tumor de Ehrlich na forma sólida, dos grupos controle, quimioterapia e eletroquimioterapia

\begin{tabular}{cccc}
\hline & Média vasos:cga* $^{*}$ & Desvio padrão & Erro padrão \\
\hline controle & 10,67 & 6,34 & 1,16 \\
quimioterapia & $14,97 \neq$ & 3,61 & 0,66 \\
eletroquimioterapia & $8,62 \neq \neq$ & 3,13 & 0,49
\end{tabular}

Legenda: *cga:campo de grande aumento (40x); ¥:diferença estatisticamente significante com $p \leq 0,01$ em relação ao controle; $\neq \neq$ : diferença estatisticamente significante com $p \leq 0,01$ em relação ao grupo quimioterapia (ANOVA/Tukey-Kramer). 
Gráfico 2 - Densidade microvascular tumoral em camundongos portadores do tumor de Ehrlich na forma sólida, tratados com quimioterapia, eletroquimioterapia e controle

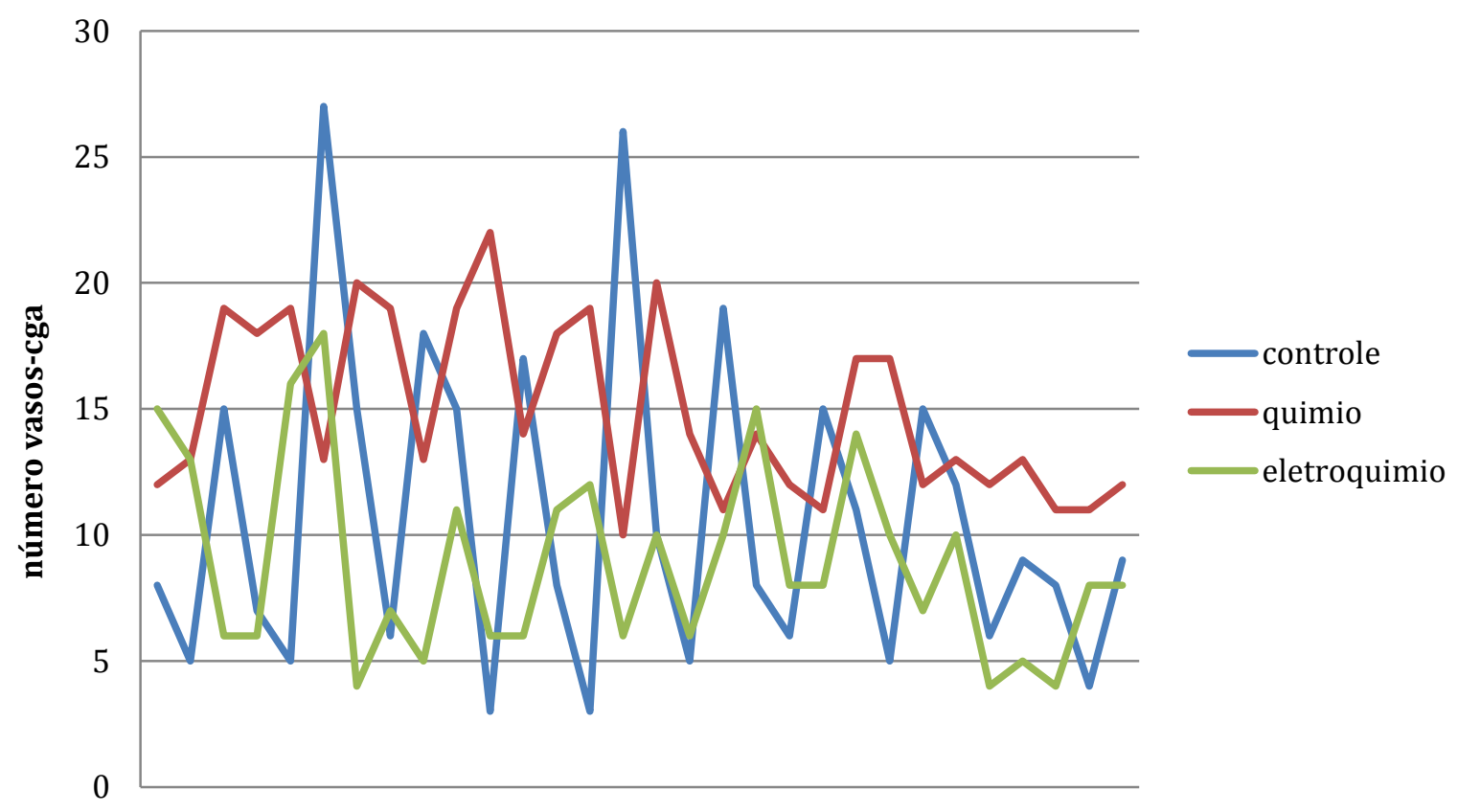

\subsection{DISCUSSÃO}

A EQT é uma modalidade de tratamento combinado utilizando quimioterapia e eletroporação (MIR; ORLOWSKI, 1999). A eletroporação aumenta a permeabilidade da membrana celular transitória e reversivelmente, permitindo a penetração do agente quimioterápico. Esse efeito perdura por alguns minutos (JAROSZESKI et al., 2001). O efeito é particularmente mais evidente mediante a utilização de quimioterápicos hidrofílicos. O aumento na captação celular foi confirmado com o emprego de cisplatina e bleomicina marcadas radioativamente (BELEHRADEK et al., 1994; CEMAZAR et al., 1999).

Embora várias drogas tenham sido empregadas em protocolos de EQT, a bleomicina é a que apresenta seus efeitos mais potencializados nessa situação (GEHL, 2003), fato que norteou nossa opção pela droga neste estudo. Também são relatados efeitos superiores da aplicação intratumoral do quimioterápico em comparação a aplicações venosas (SERSA; MIKLAVCIC, 2008). Nesse contexto, com a aplicação intratumoral da droga, a dose empregada é mínima, evitando efeitos sistêmicos. No período de observação não houve diferença estatísticas entre 
os pesos dos camundongos, sendo a sua distribuição compatível com a curva normal. Esse fato talvez possa ser levado em consideração pela baixa morbidade provocada tanto pela bleomicina quanto pela eletroquimioterapia com o mesmo fármaco, descrita com frequência na literatura (CEMAZAR et al., 2008).

A realização do procedimento de eletroporação provoca desconforto momentâneo no animal, determinando contrações musculares e dor (SERSA; MIKLAVCIC, 2008), tornando necessário o procedimento anestésico. No presente estudo utilizou-se inicialmente a associação de quetamina e xilazina na dose preconizada, porém essa associação não foi capaz de provocar analgesia suficiente, e quando se fizeram novas aplicações para maior conforto, alguns óbitos ocorreram. A posterior introdução da morfina no protocolo anestésico promoveu a analgesia necessária para a EQT. Outros animais foram descartados pelo desenvolvimento de úlceras sobre a pele tumoral devido ao crescimento exponencial do tumor de Ehrlich, esse fato levava ao traumatismo da região e a impossibilidade de se mensurar o tumor caso fosse feito algum tratamento.

O mecanismo de ação da EQT ainda é alvo de discussão, postulando-se influências sobre a vasculatura local e sobre a imunidade que otimizariam os efeitos do tratamento (CEMAZAR et al., 2001a, b; ENTIN et al., 2003; KANTHOU et al., 2006; SERSA et al., 2008a; MIKLAVCIC et al., 2010). Neste estudo não foram identificadas alterações histológicas entre animais tratados ou não com EQT, porém tal fato pode estar relacionado ao elevado grau de agressividade do tumor de Ehrlich, no qual usualmente associam-se à intensa anaplasia das células neoplásicas, extensas áreas de hemorragia e necrose, como ocorre frequentemente nos tumores sólidos de crescimento rápido (BAERISWYL; CHRISTOFORI, 2009). Assim, atividades sugeridas para explicar o efeito do procedimento, relacionadas à ruptura vascular, isquemia local e indução de apoptose estariam parcialmente mascaradas.

O emprego de apenas uma aplicação de EQT realizado neste estudo restringe os achados, visto que o antagonismo ao crescimento tumoral é menor. Potencialmente a repetição das aplicações levando à remissão parcial ou total do tumor poderia otimizar essas observações (SERSA et al., 2008b), porém o crescimento contínuo tumoral dos grupos controle e apenas quimioterapia também poderia levar a soluções de continuidade severas da pele, dificultando em muito a mensuração tumoral. O contraste entre o efeito da quimioterapia isoladamente e da 
EQT sobre o crescimento tumoral pode ser parcialmente explicado pela reconhecida baixa permeabilidade celular a bleomicina, o que limita em muito sua ação sobre o tecido tumoral (PODDEVIN et al., 1991), de fato, menos de 0,1\% da bleomicina adicionada ao meio extracelular pode ganhar o citoplasma (ROY; HORWITZ, 1984). A comparação da evolução do volume dos tumores de Ehrlich tratados com EQT e quimioterapia isolada com os animais do grupo controle apresentou relevância estatística com $\mathrm{p}<0,05$, pelos métodos aplicados, por outro viés a simples observação do gráfico 1 mostra uma tendência para maior influência sobre o desenvolvimento tumoral do grupos dos animais submetidos a EQT com bleomicina do que apenas com o quimioterápico, corroborando dados de literatura (GOTHELF; MIR; GEHL, 2003).

Com o emprego de procedimento imuno-histoquímico utilizando-se marcador de endotélio vascular, o fator VIII, observou-se imunopositividade em todos os cortes, com avaliação rigorosa das lâminas no que concerne ao padrão de marcação, visto a frequente presença de marcação de fundo, evento inerente ao marcador. Assim, admitiu-se a positividade quando do esboço da membrana basal vascular. Inicialmente foi procedida a quantificação com o método de Chalkley, porém a pequena quantidade de vasos inviabilizou o método, devido a predominante ausência de sobreposição de estruturas vasculares à gratícula (VERMEULEN et al., 2002). Em consequência optou-se pela contagem do número total de vasos em campos de grande aumento (GRAHAM; MYERS, 1999). Identificou-se uma tendência à redução da vascularização tumoral em animais submetidos à EQT, quando comparados aos do grupo controle. Já em relação ao grupo quimioterapia a diferença foi estatisticamente significante. Tais dados derivados da avaliação morfométrica foram corroborados pelas dimensões tumorais nos diferentes grupos, nos quais detectou-se uma redução de volume em camundongos tratados com EQT, em oposição ao evidenciado em animais tratados isoladamente com quimioterapia, nos quais as dimensões tumorais foram superiores as observadas no grupo nãotratado. Esses achados reforçam os estudos que posicionam a vascularização como um componente central na biologia tumoral (FOLKMAN, 1990), e a vasculatura como alvo importante na ação da EQT (CEMAZAR et al., 2001b; KANTHOU et al., 2006). 


\subsection{CONCLUSÃO}

Conclui-se que entre os tratamentos empregados e pelo método de avaliação utilizado, a eletroquimioterapia apresentou efeito antagônico sobre o crescimento neoplásico, destacando-se sua ação inibitória sobre a vascularização tumoral. 


\section{REFERÊNCIAS}

BAERISWYL, V.; CHRISTOFORI, G. The angiogenic switch in carcinogenesis. Seminars in Cancer Biology, v. 19, n. 5, p. 329-37, 2009. Disponível em: <http://www.ncbi.nlm.nih.gov/pubmed/19482086>. Acesso em: 6 nov. 2013.

BELEHRADEK JR, J.; ORLOWSKI, S.; RAMIREZ, L. H.; PRON, G.; PODDEVIN, B.; MIR, L. M. Electropermeabilization of cells in tissues assessed by the qualitative and quantitative electroloading of bleomycin, Biochemical and Biophysical Acta, v. 1190, p. 155-163, 1994.

BRUNNER, C. H. M. Equipamento e processo para aplicação de pulsos elétricos de alta voltagem para a técnica de eletroquimioterapia por eletroporação no tratamento de neoplasias. PI 0903000-0, 20 mar. 2009. Disponível em: <http://www.inpi.gov.br>. Acesso em: 26 jun. 2015.

BRUNNER, C. H. M.; DUTRA, G.; SILVA, C. B.; SILVEIRA, L. M. G.; MARTINS, M. D. F. M. Electrochemotherapy for the treatment of fibropapillomas in Chelonia mydas. Journal of zoo and wildlife medicine : official publication of the American Association of Zoo Veterinarians, v. 45, n. 2, p. 213-8, jun. 2014. Disponível em: <http://www.ncbi.nlm.nih.gov/pubmed/25000680>. Acesso em: 12 dez. 2014.

CEMAZAR, M.; MIKLAVCIC, D.; MIR, L. M.; BELEHRADEK, J.; BONNAY, M.; FOURCAULT, D.; SERSA, G. Electrochemotherapy of tumours resistant to cisplatin: a study in a murine tumour model. European Journal of Cancer, v. 37, n. 9, p. 1166-72, jun. 2001a. Disponível em:

<http://www.ncbi.nlm.nih.gov/pubmed/11378348>. Acesso em: 23 jun. 2013.

CEMAZAR, M.; MIKLAVCIC, D.; SCANCAR, J.; DOLZAN, V.; GOLOUH, R.; SERSA, G. Increased platinum accumulation in SA-1 tumour cells after in vivo electrochemotherapy with cisplatin. British journal of cancer, v. 79, n. 9-10, p. 1386-1391, 1999.

CEMAZAR, M.; PARKINS, C. S.; HOLDER, A. L.; CHAPLIN, D. J.; TOZER, G. M.; SERSA, G. Electroporation of human microvascular endothelial cells: evidence for an anti-vascular mechanism of electrochemotherapy. British Journal of Cancer, v. 84, n. 4, p. 565-70, fev. 2001b. Disponível em:

$<$ http://www.pubmedcentral.nih.gov/articlerender.fcgi?artid=2363761\&tool=pmcentre z\&rendertype=abstract>. Acesso em: 26 set. 2013.

CEMAZAR, M.; TAMZALI, Y.; SERSA, G.; TOZON, N.; MIR, L. M.; MIKLAVCIC, D.; LOWE, R.; TEISSIE, J. Electrochemotherapy in veterinary oncology. Journal of Veterinary Internal Medicine, v. 22, n. 4, p. 826-31, 2008. Disponível em: <http://www.ncbi.nlm.nih.gov/pubmed/18537879>. Acesso em: 2 abr. 2013.

ENTIN, I.; PLOTNIKOV, A.; KORENSTEIN, R.; KEISARI, Y. Tumor growth retardation, cure, and induction of antitumor immunity in B16 melanoma-bearing mice by low electric field-enhanced chemotherapy. Clinical Cancer Research, v. 9, n. 8, p. 3190-7, 1 ago. 2003. Disponível em: <http://www.ncbi.nlm.nih.gov/pubmed/12912972>. Acesso em: 12 jun. 2014. 
FOLKMAN, J. What is the evidence that tumors are angiogenesis dependent? Journal of the National Cancer Institute, v. 82, n. 1, p. 4-6, 1990.

GEHL, J. Electroporation: theory and methods, perspectives for drug delivery, gene therapy and research. Acta Physiologica Scandinavica, v. 177, n. 4, p. 437-447, 2003.

GOTHELF, A.; MIR, L. M.; GEHL, J. Electrochemotherapy: results of cancer treatment using enhanced delivery of bleomycin by electroporation. Cancer Treatment Reviews, v. 29, n. 5, p. 371-387, out. 2003. Disponível em: <http://linkinghub.elsevier.com/retrieve/pii/S0305737203000732>. Acesso em: 28 fev. 2013.

GRAHAM, J. C.; MYERS, R. K. The prognostic significance of angiogenesis in canine mammary tumors. Journal of Veterinary Internal Medicine, v. 13, n. 5, p. 416-8, 1999. Disponível em: <http://www.ncbi.nlm.nih.gov/pubmed/10499723>. Acesso em: 26 jun. 2014.

HSU, S. M.; RAINE, L.; FANGER, H. Use of avidin-biotin-peroxidase complex (ABC) in immunoperoxidase techniques: a comparison between $A B C$ and unlabeled antibody (PAP) procedures. The Journal of Histochemistry and Cytochemistry, v. 29 , n. 4 , p. 577-580, 1981.

JAROSZESKI, M. J.; COPPOLA, D.; NESMITH, G.; POTTINGER, C.; HYACINTHE, $M$. Effects of electrochemotherapy with bleomycin on normal liver tissue in a rat model. European Journal of Cancer, v. 37, p. 414-421, 2001.

KANTHOU, C.; KRANJC, S.; SERSA, G.; TOZER, G.; ZUPANIC, A.; CEMAZAR, M. The endothelial cytoskeleton as a target of electroporation-based therapies.

Molecular Cancer Therapeutics, v. 5, n. 12, p. 3145-52, dez. 2006. Disponível em: <http://www.ncbi.nlm.nih.gov/pubmed/17172418>. Acesso em: 14 nov. 2013.

MARTY, M.; SERSA, G.; GARBAY, J. R.; GEHL, J.; COLLINS, C. G.; SNOJ, M.; BILLARD, V.; GEERTSEN, P. F.; LARKIN, J. O.; MIKLAVCIC, D.; PAVLOVIC, I.; PAULIN-KOSIR, S. M.; CEMAZAR, M.; MORSLI, N.; SODEN, D. M.; RUDOLF, Z.; ROBERT, C.; O'SULLIVAN, G. C.; MIR, L. M. Electrochemotherapy - An easy, highly effective and safe treatment of cutaneous and subcutaneous metastases:

Results of ESOPE (European Standard Operating Procedures of Electrochemotherapy) study. European Journal of Cancer Supplements, v. 4, n. 11, p. 3-13, nov. 2006. Disponível em:

<http://linkinghub.elsevier.com/retrieve/pii/S1359634906001868>. Acesso em: 16 fev. 2013.

MEULENBERG, C. J. W.; TODOROVIC, V.; CEMAZAR, M. Differential cellular effects of electroporation and electrochemotherapy in monolayers of human microvascular endothelial cells. PLoS ONE, v. 7, n. 12, p. e52713, 27 dez. 2012. Disponível em: <http://dx.plos.org/10.1371/journal.pone.0052713>. Acesso em: 26 jun. 2014. 
MIDDLETON, J.; AMERICH, L.; GAYON, R.; JULIEN, D.; MANSAT, M.; MANSAT, P.; ANRACT, P.; CANTAGREL, A.; CATTAN, P.; REIMUND, J. M.; AGUILAR, L.; AMALRIC, F.; GIRARD, J. P. A comparative study of endothelial cell markers expressed in chronically inflamed human tissues: MECA-79, Duffy antigen receptor for chemokines, von Willebrand factor, CD31, CD34, CD105 and CD146. Journal of Pathology, v. 206, n. 3, p. 260-268, 2005.

MIKLAVCIC, D.; SNOJ, M.; ZUPANIC, A.; KOS, B.; CEMAZAR, M.; KROPIVNIK, M.; BRACKO, M.; PECNIK, T.; GADZIJEV, E.; SERSA, G. Towards treatment planning and treatment of deep-seated solid tumors by electrochemotherapy. Biomedical Engineering Online, v. 9, p. 10, jan. 2010. Disponível em: $<$ http://www.pubmedcentral.nih.gov/articlerender.fcgi?artid=2843684\&tool=pmcentre z\&rendertype=abstract $>$. Acesso em: 15 set. 2013.

MIR, L. M.; GEHL, J.; SERSA, G.; COLLINS, C. G.; GARBAY, J.-R.; BILLARD, V.; GEERTSEN, P. F.; RUDOLF, Z.; O'SULLIVAN, G. C.; MARTY, M. Standard operating procedures of the electrochemotherapy: Instructions for the use of bleomycin or cisplatin administered either systemically or locally and electric pulses delivered by the CliniporatorTM by means of invasive or non-invasive electrodes.

European Journal of Cancer Supplements, v. 4, n. 11, p. 14-25, nov. 2006. Disponível em: <http://linkinghub.elsevier.com/retrieve/pii/S135963490600187X>. Acesso em: 21 out. 2012.

MIR, L. M.; ORLOWSKI, S. Mechanisms of electrochemotherapy. Advanced Drug Delivery Reviews, v. 35, n. 1, p. 107-118, jan. 1999. Disponível em: <http://linkinghub.elsevier.com/retrieve/pii/S0169409X98000660>. Acesso em: 15 set. 2013.

MIR, L. M.; TOUNEKTI, O.; ORLOWSKI, S. Bleomycin: revival of an old drug.

General pharmacology, v. 27, n. 5, p. 745-8, jul. 1996. Disponível em: <http://www.ncbi.nlm.nih.gov/pubmed/8842674>. Acesso em: 26 jun. 2014.

PODDEVIN, B.; ORLOWSKI, S.; BELEHRADEK, J.; MIR, L. M. Very high cytotoxicity of bleomycin introduced into the cytosol of cells in culture. Biochemical

Pharmacology, v. 42 Suppl, p. S67-75, 11 dez. 1991. Disponível em: <http://www.ncbi.nlm.nih.gov/pubmed/1722669>. Acesso em: 26 jun. 2014.

ROY, S. N.; HORWITZ, S. B. Characterization of the association of radiolabeled bleomycin A 2 with HeLa cells. Cancer Research, v. 44, p. 1541-1546, 1984.

RUGGERI, M. Z. ;WARE. J. Von Willebrand factor. The FASEB Journal, v. 7, p. 308, 316, 1993.

RUITER, D. J.; SCHLINGEMANN, R. O.; RIETVELD, F. J.; DE WAAL, R. M. Monoclonal antibody-defined human endothelial antigens as vascular markers. The Journal of Investigative Dermatology, v. 93, n. 2, p. 25S-32S, 1989. Supplement.

SERSA, G.; CEMAZAR, M.; MIKLAVCIC, D. Tumor blood flow modifying effects of electrochemotherapy: a potential vascular targeted mechanism. Radiology and Oncology, v. 37, n. 1, p. 43-48, 2003. 
SERSA, G.; CEMAZAR, M.; SEMROV, D.; MIKLAVCIC, D. Changing electrode orientation improves the efficacy of electrochemotherapy of solid tumors in mice. Bioelectrochemistry and Bioenergetics, v. 39, p. 61-66, 1996.

SERSA, G.; JARM, T.; KOTNIK, T.; COER, a; PODKRAJSEK, M.; SENTJURC, M.; MIKLAVCIC, D.; KADIVEC, M.; KRANJC, S.; SECEROV, a; CEMAZAR, M. Vascular disrupting action of electroporation and electrochemotherapy with bleomycin in murine sarcoma. British Journal of Cancer, v. 98, n. 2, p. 388-98, 29 jan. 2008 a. Disponível em:

$<$ http://www.pubmedcentral.nih.gov/articlerender.fcgi?artid=2361464\&tool=pmcentre z\&rendertype=abstract>. Acesso em: 16 fev. 2013.

SERSA, G.; KRZIC, M.; SENTJURC, M.; IVANUSA, T.; BERAVS, K.; KOTNIK, V.; COER, A.; SWARTZ, H. M.; CEMAZAR, M. Reduced blood flow and oxygenation in SA-1 tumours after electrochemotherapy with cisplatin. British Journal of Cancer, v. 87, n. 9, p. 1097-1054, 2002.

SERSA, G.; MIKLAVCIC, D. Electrochemotherapy of tumours. Journal of Visualized Experiments : JoVE, n. 22, p. 9-10, jan. 2008. Disponível em: <http://www.pubmedcentral.nih.gov/articlerender.fcgi?artid=2762922\&tool=pmcentre z\&rendertype=abstract>. Acesso em: 4 out. 2012.

SERSA, G.; MIKLAVCIC, D.; CEMAZAR, M.; RUDOLF, Z.; PUCIHAR, G.; SNOJ, M. Electrochemotherapy in treatment of tumours. European Journal of Surgical Oncology, v. 34, n. 2, p. 232-240, 2008b.

SILVEIRA, L. M. G.; BRUNNER, C. H. M.; FUTEMA, F. Utilização de eletroquimioterapia em neoplasias de origem epitelial ou mesenquimal localizadas em pele ou mucosas de cães. Brazilian Journal of Veterinary Research and Animal Science, v. 47, n. 1, p. 55-66, 2010.

TOUNEKTI, O.; PRON, G.; BELEHRADEK, J.; MIR, L. M. Bleomycin , an apoptosismimetic drug that induces two types of cell death depending on the number of molecules internalizeds. Cancer Research, v. 53, p. 5462-5469, 1993.

VERMEULEN, P. B.; GASPARINI, G.; FOX, S. B.; COLPAERT, C.; MARSON, L. P.; GION, M.; BELIËN, J. A. M.; DE WAAL, R. M. W.; VAN MARCK, E.; MAGNANI, E.; WEIDNER, N.; HARRIS, A L.; DIRIX, L. Y. Second international consensus on the methodology and criteria of evaluation of angiogenesis quantification in solid human tumours. European Journal of Cancer, 2002.

WARHOL, M. J.; SWEET, J. M. Ultrastructural Localization of von Willebrand Factor in Endothelial Cells. The American Journal of Pathology, v. 117, n. 2, p. 310-315, 1984.

YAMAMOTO, K.; DE WAARD, V.; FEARNS, C.; LOSKUTOFF, D. J. Tissue distribution and regulation of murine von Willebrand factor gene expression in vivo. Blood, v. 92, n. 8, p. 2791-2801, 1998. 


\section{Efeito da eletroquimioterapia e de sua combinação com o resveratrol sobre o desenvolvimento do tumor de Ehrlich na forma sólida em camundongos}

\section{RESUMO}

A eletroquimioterapia (EQT) é uma modalidade de tratamento combinada, baseada no uso de quimioterapia e eletroporação, de uso crescente em pacientes oncológicos. A eletroporação baseia-se na aplicação de pulsos elétricos em células ou tecidos, tornando as membranas celulares transitoriamente permeáveis, facilitando o ingresso de moléculas pouco absorvíveis em condições naturais, como as de bleomicina, um potente quimioterápico. Já o resveratrol (Rv) é um composto fenólico natural, encontrado em concentrações elevadas na uva, amendoim e vinho tinto, com elevado potencial terapêutico, apresentando efeitos anti-inflamatórios, antiplaquetários, e, em particular, antitumorais. Neste estudo, avaliou-se o efeito da eletroquimioterapia e do resveratrol, isoladamente e em associação, sobre o desenvolvimento do tumor de Ehrlich em sua forma sólida em camundongos. Foram utilizados 30 camundongos BALB-c, que receberam inóculo subcutâneo de 0,1 mL de solução contendo $5,0 \times 10^{6}$ células do tumor de Ehrlich. Após 30 dias de crescimento tumoral os animais foram divididos de forma aleatória em grupos: controle tumoral $(C)$; poração $(P)$; quimioterapia $(Q)$; resveratrol $(R)$; eletroquimioterapia (E) e o grupo eletroquimioterapia/resveratrol (ER). O volume tumoral foi mensurado antes do tratamento e sete dias após, com a eutanásia ao fim do período. Os tumores foram processados histologicamente, avaliando-se a morfologia tumoral e atividade proliferativa por contagem mitótica. Em complemento foi avaliada a expressão de VEGF-A por método imuno-histoquímico. Os animais submetidos a tratamento apresentaram, após 7 dias, redução na progressão tumoral (ANOVA, Kruskal-Wallis), com $p<0,05$ entre $C$ e $R$ assim como $C$ e $E$, e $p<0,01$ entre C e ER, sendo a menor expansão tumoral identificada no grupo ER. Microscopicamente evidenciou-se semelhança entre os diferentes grupos, com tendência à redução na atividade proliferativa em animais do grupo ER. Nestes e 
nos animais do grupo $R$ observou-se redução na expressão de VEGF-A. Ambas as abordagens, E e R, exibem em comum o potencial de atuação sobre o componente vascular do microambiente tumoral, porém por mecanismos distintos, envolvendo ação mecânica e indução apoptótica na primeira e antagonização da angiogênese na última, via ativação de sirtuina-1 e subsequente inibição de $H I F-1 \alpha$, culminando com a redução na expressão de VEGF. Em suma, a eletroquimioterapia e o resveratrol determinaram redução na progressão tumoral, com tendência a um efeito superior em animais tratados com a associação dos dois procedimentos.

Palavras-chave: Oncologia experimental. Eletroquimioterapia. Resveratrol. Vascularização.

\subsection{REVISÃO DE LITERATURA}

A eletroquimioterapia tem sido pesquisada desde 1991 como mais uma possibilidade no arsenal terapêutico oncológico, tendo como princípio a eletroporação como potencializadora da ação de alguns quimioterápicos (MIR; ORLOWSKI, 1999). A membrana citoplasmática torna-se mais permeável de maneira fugaz por meio da aplicação de pulsos elétricos parametrizados, em fenômeno designado eletroporação, ao ingresso de moléculas pouco absorvíveis em condições naturais como a bleomicina (MIR, 2000), um potente quimioterápico que tem sua entrada celular drasticamente reduzida pela membrana citoplasmática (MIR; TOUNEKTI; ORLOWSKI, 1996), provavelmente pela natureza hidrofílica desse fármaco (PODDEVIN et al., 1991). Mediante a eletroporação, a bleomicina entra livremente na célula (MIR, 2006), potencializando sua citotoxicidade centenas de vezes (MIR et al., 1991), antagonizando o crescimento tumoral, particularmente por via apoptótica (TOUNEKTI et al., 1993). Um evento paralelo induzido pela aplicação de pulsos elétricos associados ao uso da bleomicina, é uma severa redução no fluxo sanguíneo local, com retorno à normalidade em 24 horas, sugerindo-se sua participação complementar no efeito da eletroquimioterapia, por estender o tempo de ação do quimioterápico (SERSA et al., 2002). A baixa perfusão ocorre de maneira 
fugaz quando da aplicação apenas de pulsos elétricos (SERSA et al., 1999) e não é observada pela aplicação exclusiva de bleomicina (SERSA; CEMAZAR; MIKLAVCIC, 2003). A hipóxia tumoral é um fator para se estabelecer prognóstico e tem sido relacionada a tumores de crescimento agressivo, metastáticos e de pouca respostas às terapias (HÖCKEL et al., 1996). O papel da hipóxia na regulação da expressão dos genes é de potencial importância para o entendimento desses efeitos (HANAHAN; FOLKMAN, 1996). Estudos de expressão genética tem encontrado várias classes de genes que são supra regulados em regiões de hipóxia tumoral e demonstram que a ativação do complexo transcricional fator induzido por hipóxia (HIF) é o mediador central de muitos desses fenômenos (CARMELIET; COLLEN, 1998). O HIF é uma proteína heterodimérica classificada em HIF- $\alpha$ e HIF- $\beta$ (WANG et al., 1995) sendo HIF $\alpha$ sub-classificado em três isoformas: HIF1- $\alpha$ HIF2- $\alpha$ e HIF3- $\alpha$ sendo o HIF1- $\alpha$ a subunidade mais estudada (CUMMINS; TAYLOR, 2005).

O resveratrol é um composto derivado da uva, relacionado ao aumento da sobrevida em fungos, helmintos, moscas e roedores (HAN et al., 2015). O seu mecanismo de ação não é completamente conhecido, porém parte de sua atividade relaciona-se a ativação da sirtuina 1 (GERTZ et al., 2012). As sirtuinas integram um grupo de deacetilases dependentes de nicotinamida adenina dinucleotídeo (NAD), o que as vincula ao metabolismo celular, relacionando-se ao silenciamento gênico, a morte celular, longevidade, inflamação e câncer (HOUTKOOPER; PIRINEN; AUWERX, 2012). De particular interesse no âmbito da biologia tumoral é a modulação pelas sirtuinas da atividade do fator transcricional HIF-1 $\alpha$, diretamente relacionado à progressão tumoral (TAFANI et al., 2013). Em células bem oxigenadas, HIF é uma proteína com meia vida inferior a 5 minutos e seu nível básico é muito baixo. Porém quando da disponibilidade reduzida de $\mathrm{O}_{2}$, o HIF tem seus níveis elevados por diminuição de sua degradação via ubiquitina-proteassoma (KOSHIJI; HUANG, 2004; BENIZRI; GINOUVÈS; BERRA, 2008). Um evento central relacionado a atividade de HIF1- $\alpha$ é a mediação do processo de neovascularização tumoral (BRANCO-PRICE et al., 2012). Decorrente da hipóxia ocorre aumento do HIF1- $\alpha$, que por sua vez eleva a expressão do fator de crescimento endotelial vascular (VEGF), fenômeno esse que é atenuado pelo resveratrol (PARK et al., 2007). O VEGF apresenta aparentemente 7 isoformas, sendo que 4 delas apresentam maior relevância vascular. O VEGF-A é a isoforma conhecida mais 
importante para a angiogênese de vasos sanguíneos, o VEGF-B possui maior ação na manutenção dos novos vasos, o VEGF-C e o VEGF-D regulam a linfoangiogênse (FERRARA; GERBER; LECOUTER, 2003). A relação da hipóxia com, a modulação da expressão desses fatores pode representar uma importante alternativa terapêutica no tratamento de pacientes oncológicos (TAFANI et al., 2013).

Considerando-se o comprometimento da perfusão vascular associado ao processo de eletroquimioterapia, e a potencial atividade do resveratrol antagonizando o HIF-1 $\alpha$, a associação entre os dois procedimentos poderia otimizar a atividade do tratamento antitumoral. $O$ presente estudo avalia o efeito da eletroquimioterapia e do resveratrol, isoladamente e em associação, sobre o desenvolvimento do tumor de Ehrlich na forma sólida em camundongos.

\subsection{MATERIAL E MÉTODO}

\subsubsection{ANIMAIS}

Foram utilizados 30 camundongos BALB-c, fêmeas, pesando entre 25 e $30 \mathrm{~g}$, mantidos no Biotério da Universidade Paulista sob ciclo invertido, com condições de iluminação controlada, temperatura entre 20 e $25^{\circ} \mathrm{C}$ e umidade relativa entre $55 \mathrm{a}$ $65 \%$, recebendo ração ${ }^{10}$ e água "ad libitum". Os camundongos foram divididos em 6 grupos com 5 animais cada: controle $(C)$, quimioterapia $(Q)$, eletroporação $(P)$, resveratrol $(R)$, eletroquimioterapia $(E)$ e resveratrol associado à eletroquimioterapia (ER).

\subsubsection{Tumor de Ehrlich}

Os animais receberam inóculo subcutâneo de $0,1 \mathrm{~mL}$ de solução contendo $5,0 \times 10^{6}$ células do tumor de Ehrlich. Após 30 dias de crescimento tumoral os animais foram divididos aleatoriamente nos 6 grupos, tiveram seus volumes tumorais

\footnotetext{
${ }^{10}$ Biobase $9310 \mathrm{~A}$ - Biobase Nutrição Animal, Aguas Claras, SP
} 
calculados e foram submetidos ao tratamento. Para a determinação do volume tumoral, foi utilizado um paquímetro, aplicando-se a fórmula: V=L.E.P. $\square: 6000$, sendo: $V=$ volume $\left(\mathrm{cm}^{3}\right)$; L=largura $(\mathrm{mm}) ; E=$ espessura $(\mathrm{mm}) ; P=$ profundidade $(\mathrm{mm})$.

\subsubsection{Tratamento}

Os camundongos do grupo quimioterapia receberam bleomicina ${ }^{11}$ na dose de $1 \mathrm{U} / \mathrm{cm}^{3}$ de tumor por via intralesional. O grupo resveratrol recebeu inóculo intraperitoneal único de $0,1 \mathrm{ml}$ de resveratrol $(10 \mathrm{mg} / \mathrm{kg}$ suspenso em DMSO). Nos demais grupos os animais foram anestesiados, com associação de quetamina ${ }^{12}$, xilazina $^{13}$ e morfina ${ }^{14}$, na dose de 2,5 mg, 1,0 mg e 0,3 mg respectivamente, para cada $100 \mathrm{~g}$ de animal, por via intraperitoneal. Os animais do grupo eletroporação, após a anestesia, receberam, aplicação de seqüências de oito pulsos elétricos de 100 us cada, em onda quadrada monopolar de $1000 \mathrm{~V} / \mathrm{cm}$, com freqüência de $1 \mathrm{~Hz}$, por meio de gerador de pulso ${ }^{15}$ (BRUNNER, 2009). Para o grupo eletroquimioterapia houve aplicação intratumoral de bleomicina mais eletroporação local imediata e no grupo eletroquimioterapia mais resveratrol a associação das duas terapias supra citadas.

\subsubsection{Avaliação macroscópica}

Após sete dias pós-tratamento cinco animais de cada grupo foram eutanasiados com isofluorano, os tumores mensurados, colhidos e submetidos à fixação em solução de formol a 10\%. A evolução tumoral após 7 dias foi calculada a partir da razão entre volume final tumoral (Vf) e volume inicial tumoral (Vi).

\footnotetext{
${ }^{11}$ Cinaleo®- Meizler UCB Biopharma SA, Barueri, SP

${ }^{12}$ Dopalen $\AA$ - Vetbrands Produtos Farmacêuticos, Paulinia - SP

${ }^{13}$ Xilazin ${ }^{\circledR}$-Syntec Produtos Farmacêuticos, Cotia - SP

${ }^{14}$ Dimorf® - Cristalia Produtos Químicos Farmacêuticos, Itapira, SP

${ }^{15}$ BK 100®- LC Pesquisa ME, São Paulo, SP
} 


\subsubsection{Avaliação histológica}

\subsubsection{Atividade proliferativa}

Após processamento histológico de rotina, corando-se os cortes pela hematoxilina/eosina, a atividade proliferativa foi avaliada pela contagem de mitoses em 10 campos de grande aumento por animal.

\subsubsection{Expressão de VEGF-A}

Para processamento imuno-histoquímico as lâminas sofreram desparafinização, recuperação antigênica por calor e bloqueio de peroxidase endógena com $\mathrm{H}_{2} \mathrm{O}_{2}$ a $3 \%$. Em seguida houve incubação com anticorpos primários policlonal anti-VEGF-A (Santa Cruz, cat\# sc152, CA, EUA), 1:100 em PBS, amplificação com NovoLink polimer, revelação com DAB (Sigma, cat\# D-5637, EUA) e posteriormente os cortes foram contracorados com hematoxlina de Harris.

A expressão de VEGF-A foi avaliada através de método quantitativo e semiquantitativo (SOINI et al., 2001; SAMPAIO-GÓES et al., 2005), observando-se as amostras em 10 campos à objetiva de 40 aumentos. Para determinação qualitativa (intensidade de coloração) os tumores foram divididos em 5 grupos: 0, marcação ausente; 1, mínima marcação; 2, marcação leve; 3, marcação moderada; 4, marcação intensa. A percentagem de área apresentando imunorreatividade foi considerada: 0 para marcação ausente; 1 para menos $25 \%$ da área imunomarcada; 2 entre 25 - 50\% da área imunomarcada; 3 entre 50-75\% da área imunomarcada e 4 para mais que $75 \%$ da área imunomarcada. Em sequência as pontuações foram somadas, resultando nos seguintes escores: $0=$ marcação ausente; $1=$ imunorreatividade fraca (soma de escalas de 1 a 4); 2 = imunorreatvidade intensa (soma de escalas de 0 a 8 ). 


\subsection{ANÁLISE ESTATÍSTICA}

Os resultados obtidos foram submetidos à análise estatística utilizando-se a ANOVA, teste de Kruskal-Wallis e Tukey-Kramer.

\subsection{RESULTADOS}

Todos os animais submetidos a tratamento apresentaram, após 7 dias, redução na progressão tumoral com diferença estatisticamente significante (ANOVA, Kruskal-Wallis), entre controle e resveratrol associado a eletroquimioterapia, entre controle e o resveratrol assim como entre o controle e a eletroquimioterapia (Tabela 4, Figura 6), sendo a menor expansão tumoral identificada no grupo eletroquimioterapia e resveratrol associados.

Tabela 4 - Evolução do volume tumoral de camundongos BAB-c portadores do tumor de Ehrlich na forma sólida em 7 dias

\begin{tabular}{lc}
\hline Grupo (n) & $\begin{array}{c}\text { Média e erro médio da evoluç } \\
\text { tumoral }\end{array}$ \\
\hline Controle (5) & $4,92 \pm 1,25$ \\
Poração (5) & $2,46 \pm 0,27$ \\
Quimioterapia (5) & $2,67 \pm 0,54$ \\
Eletroquimioterapia (5) & $1,15 \pm 0,32^{*}$ \\
Resveratrol (5) & $1,47 \pm 0,25^{*}$ \\
Eletroquimioterapia e resveratrol (5) & $1,11 \pm 0,23^{\star *}$
\end{tabular}

Relevância estatística com $\mathrm{p}<0,05^{*}$ e $\mathrm{p}<0,01^{* *}$ entre o grupo controle e os analisados (ANOVA, Kruskal-Wallis) 
Gráfico 3 - Desenvolvimento neoplásico do tumor de Ehrlich na forma sólida em camundongos BAB-c em 7 dias

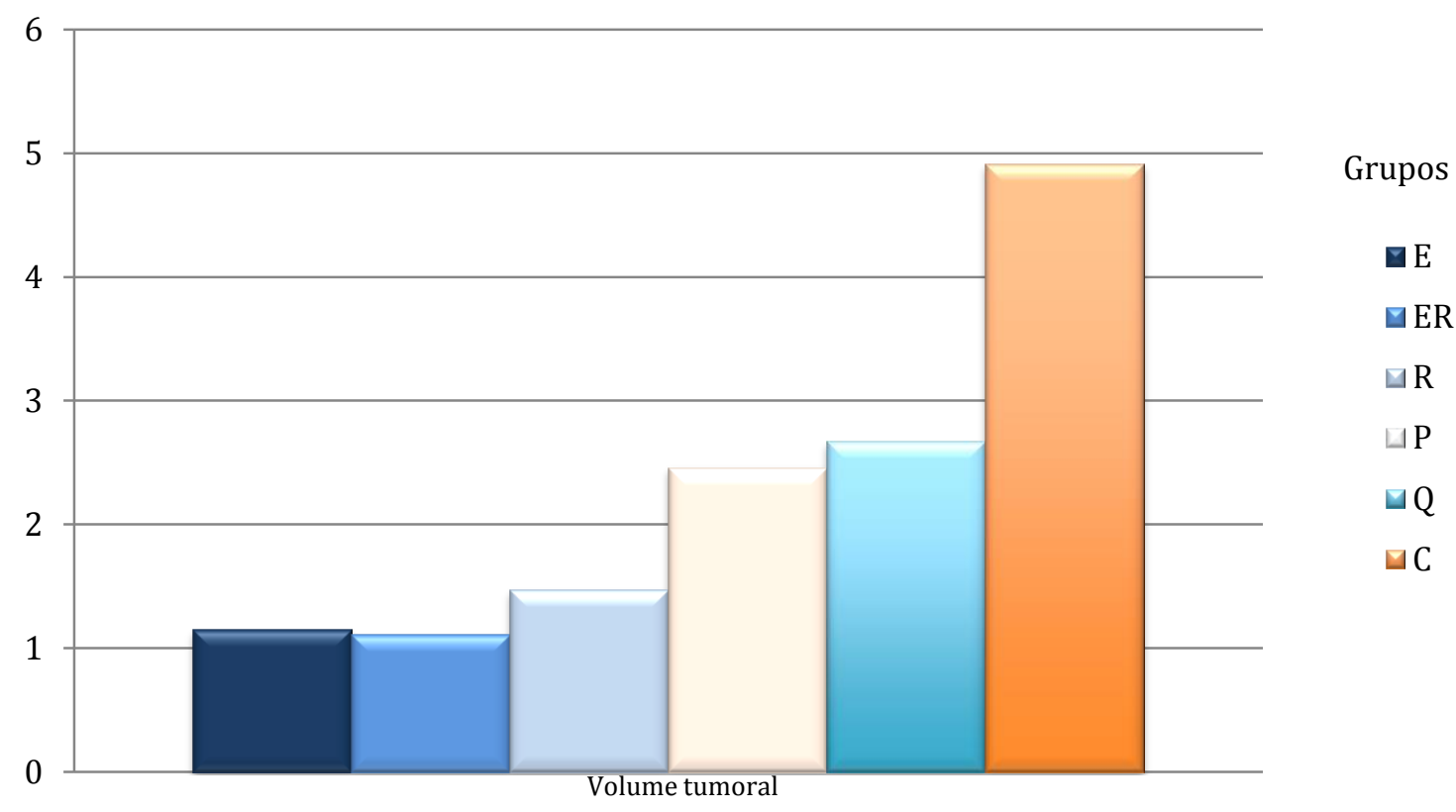

Valores obtidos da razão do volume final tumoral pelo volume inicial: C, controle; $Q$, quimioterapia ; P, eletroporação; R, resveratrol; ER, eletroquimioterapia mais resveratrol; E, eletroquimioterapia.

Histologicamente identificou-se extensa necrose nas áreas centrais do tumor, em todos os animais, observando-se população neoplásica íntegra em sítios periféricos, em particular nas cercanias vasculares (Figura 6). A atividade mitótica foi quantificada buscando-se áreas livres de necrose em campos de grande aumento (Tabela 5).

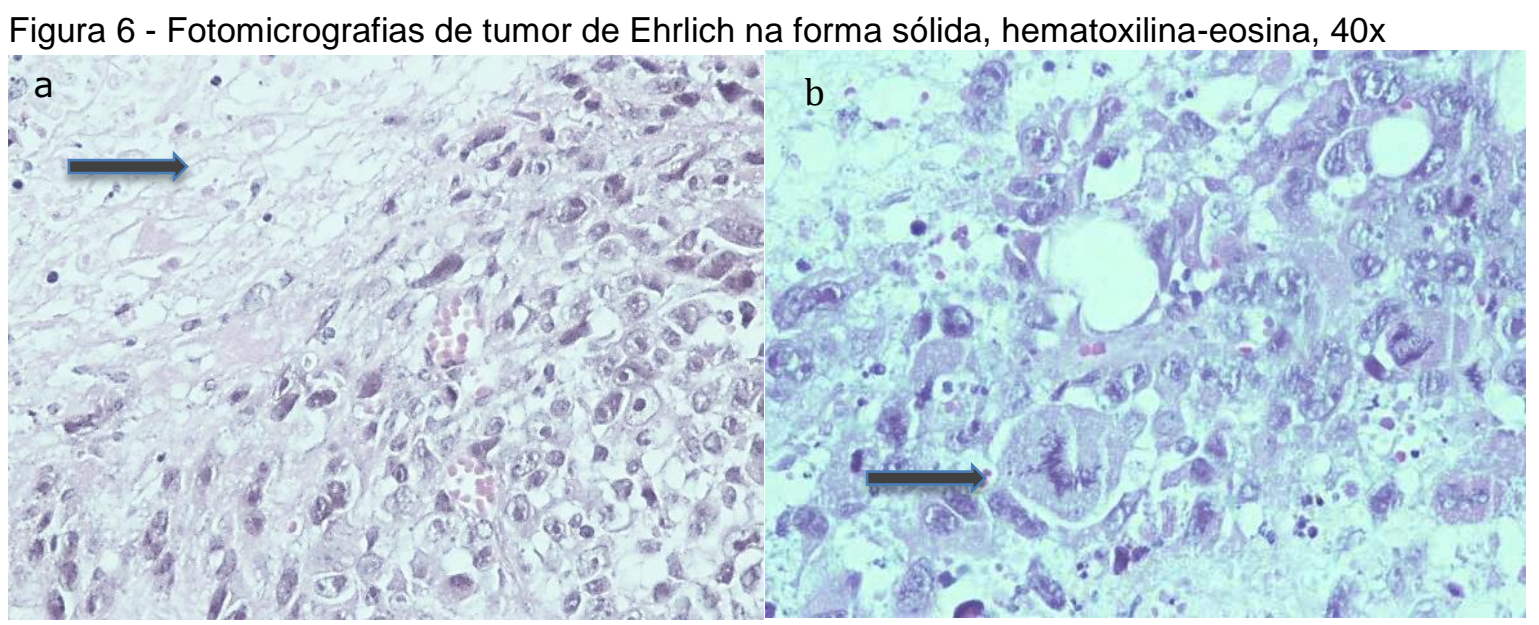

Fonte: XAVIER, J. G.

Em "a", área central necrótica (seta), com a presença de células neoplásicas íntegras em periferia. Em "b" observa-se população neoplasia pleomórfica com frequentes figuras de mitose atípicas (seta) 
Tabela 5 - Media da atividade proliferativa por grupo, a partir da contagem de mitoses em 10 campos de grande aumento

\begin{tabular}{lc}
\hline \multicolumn{1}{c}{ Grupo } & 7 dias pós-tratamento \\
\hline Controle & $27,6 \pm 2,23$ \\
Quimioterapia & $28,8 \pm 4,88$ \\
Eletroporação & $23,6 \pm 5,71$ \\
Eletroquimioterapia & $23,6 \pm 2,60$ \\
Resveratrol & $28,2 \pm 3,07$ \\
Eletroquimioterapia + resveratrol & $19,0 \pm 2,48$ \\
\hline
\end{tabular}

Não houve diferença estatisticamente significante entre os grupos, ANOVA

A partir da imunomarcação evidenciou-se hegemônica expressão de VEGF-A nas células tumorais, com intensidade variável, identificando-se importante redução na expressão em células neoplásicas de animais submetidos ao tratamento com o resveratrol, tanto isoladamente quanto em associação com a eletroquimioterapia (Tabela 6 e Figura 7).

Tabela 6 - Avaliação da imunomarcação com VEGF-A em camundongos portadores do tumor de Ehrlich na forma sólida em 7 dias

Grupo Média e erro médio da expressão de VEGF-A em células tumorais após 7 dias após tratamento

\begin{tabular}{lc}
\hline Controle & $7,0 \pm 0$ \\
Eletroquimioterapia & $7,17 \pm 0,3$ \\
Resveratrol & $6,0 \pm 0^{*}$ \\
Eletroquimioterapia + resveratrol & $5,25 \pm 0,25^{\star *}$ \\
\hline
\end{tabular}

Redução estatisticamente significante em animais do grupo resveratrol e eletroquimioterapia mais resveratrol, em relação ao grupo controle, respectivamente, ${ }^{*} p<0,05$ e ${ }^{* *} p<0,001$ (ANOVA, TukeyKramer) 
Figura 7 - Fotomicrografias de tumor de Ehrlich na forma sólida, DAB contra-corado com hematoxlina de Harris, 40x

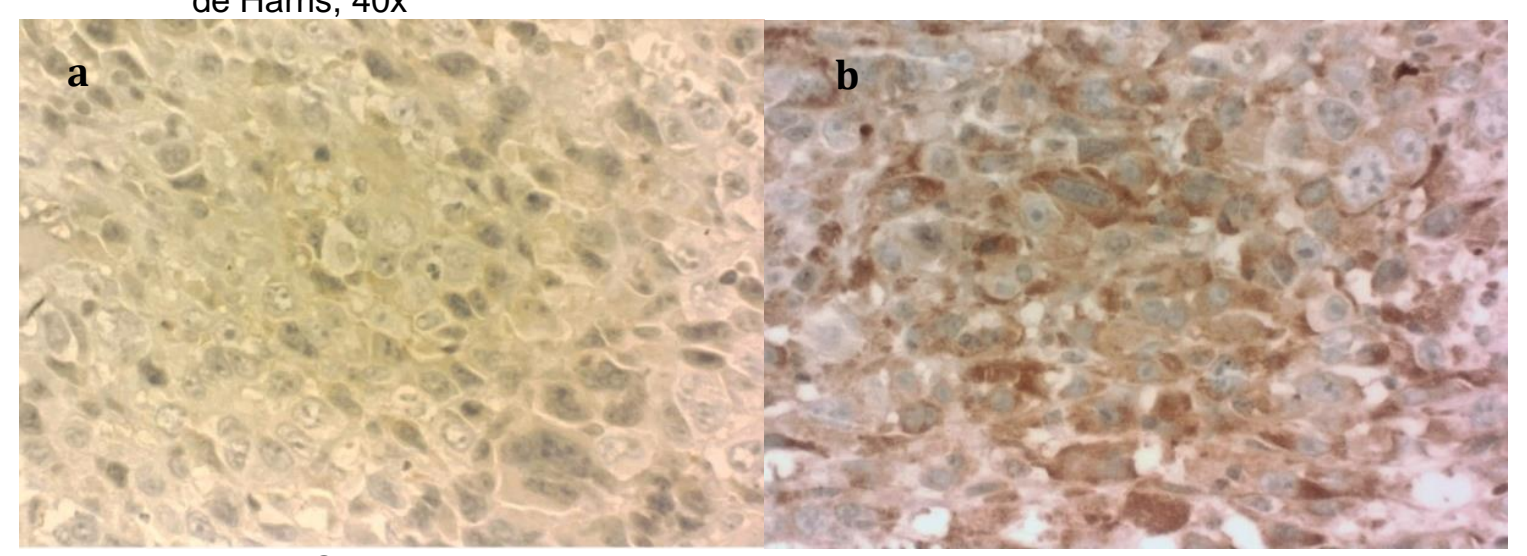

Fonte: XAVIER, J. G.

Em "a", fraca expressão citoplasmática, difusa para VEGFA, em animal do grupo eletroquimioterapia + resveratrol. Em "b" observa-se população neoplásica apresentando intensa expressão citoplasmática de VEGFA difusamente em animal do grupo controle.

\subsection{DISCUSSÃO}

A eletroquimioterapia tem sido descrita como uma modalidade efetiva, pela potencialização da citotoxicidade da bleomicina, para tratamento de tumores sólidos superficiais (MIR, 2006) indo ao encontro das observações desse experimento. Os animais dos grupos eletroporação e quimioterapia com bleomicina não apresentaram relevância estatística com o grupo controle quanto ao desenvolvimento tumoral e atividade proliferativa, conforme as descrições em literatura sobre a ineficiência dessas duas técnicas sem o emprego consorciado de ambas (GOTHELF; MIR; GEHL, 2003). A eletroquimioterapia e resveratrol apresentaram, isoladamente e em associação, a capacidade de interferir no desenvolvimento do tumor de Ehrlich na forma sólida em camundongos.

Embora no mesmo sentido de redução da progressão do tumor de Ehrlich, a eletroquimioterapia possui mecanismo distinto do resveratrol. Apoptose tem sido citada como o efeito principal da bleomicina sobre as células tumorais, e também necrose em menor grau, quando potencializada pela eletroporação (MIR; TOUNEKTI; ORLOWSKI, 1996). Na presente pesquisa evidenciou-se necrose em grande extensão e em todos os grupos, inclusive no controle, e embora não tenha sido mensurada, ocorreu provavelmente pelo descompasso entre proliferação celular e neovascularização, característico de neoplasias indiferenciadas como o 
tumor de Ehrlich. Em estudo anterior nosso grupo identificou uma redução na densidade microvascular no microambiente tumoral em animais submetidos a eletroquimioterapia intratumoral, evento que potencialmente agrava a condição de hipóxia local. Conforme já referido, em condições de hipóxia há estabilização das moléculas de HIF1- $\alpha$, envolvidas na modulação do metabolismo as células tumorais, incrementando a expressão de VEGF (BRANCO-PRICE et al. 2012). Nos tumores dos animais pesquisados houve redução da expressão de VEGF-A nos grupos resveratrol e, de maneira mais intensa, no resveratrol associado à eletroquimioterapia com bleomicina. Essa resposta pode ser fundamentada pela estimulação das sirtuinas pelo resveratrol (GERTZ et al., 2012). A sirtuina-1 modula a angiogênese pela inibição do $\operatorname{HIF} 1-\alpha$, reduzindo sua estabilização e portanto facilitando a sua degradação (TAFANI et al., 2013). O HIF1- $\alpha$ tende a se tornar mais estável no citoplasma por estímulo de hipóxia em mecanismo pós-transcricional (EVANS; BRANCO-PRICE; JOHNSON, 2012), estimulando a angiogênese, via maior expressão de VEGF (FERRARA; GERBER; LECOUTER, 2003). O resveratrol, provavelmente por inibir indiretamente o HIF1- $\alpha$, promoveu menor expressão de VEGF-A em ambos os grupos de tratamentos em que foi aplicado, E e ER. De maneira peculiar, a expressão de VEGF-A observada no grupo ER foi ainda menor que apenas o tratamento com resveratrol. A eletroquimioterapia com bleomicina possui, além da indução de apoptose e necrose (MEKID et al., 2003), também efeito vascular, reduzindo de maneira acentuada, ao ponto de ser descrita na literatura como bloqueio vascular (GEHL; SKOVSGAARD; MIR, 2002), a perfusão do tecido tumoral por ao menos 24 horas, tanto por vasoconstrição por estímulo elétrico (SERSA et al., 1999), como por lesão vascular decorrente de maior captação de bleomicina pelas células endoteliais através da eletroporação (JARM et al., 2010). A ação vascular tumoral ocasionada pela eletroquimioterapia tende a provocar hipóxia tecidual, por um tempo mínimo de 24 horas, atuando como um potencial estímulo para maior expressão de VEGF-A e angiogênese. De fato, embora não haja diferença estatística entre os grupos controle e eletroquimioterapia, esse último foi o que apresentou maior expressão de VEGF-A entre os pesquisados. Por outro lado, quando associada ao resveratrol houve menor expressão acentuando a tendência de inibição do VEGF-A pelo resveratrol. O mecanismo que possibilitou menor expressão de VEGF-A, no grupo ER, não pode ser esclarecido por essa 
experimentação, pois não apenas a indução dos efeitos de morte celular ocasionados pela eletroquimioterapia podem ter sido sinérgicos com o mecanismo de inibição do HIF1- $\alpha$ pelo resveratrol, como também a própria eletroporação pode ter permitido maior acesso do resveratrol, mesmo que aplicado por via intraperitoneal, ao citoplasma das células neoplásicas, em mecanismo similar ao da potencialização da bleomicina por eletroporação quando aplicada por via intravenosa (TESTORI et al., 2010). A progressão de um tumor ocorre basicamente por desequilíbrio entre os mecanismos de morte, incluindo a apoptose, e de proliferação (HANAHAN; WEINBERG, 2011) parcialmente dependentes da angiogênese (GACCHE, 2015). A mensuração da atividade proliferativa avaliada nessa pesquisa não demostra diferença, com relevância estatística, entre os grupos, embora exista um tendência de redução no grupo ER, ressaltando-se a referência, na literatura, de atividade antiproliferativa do resveratrol em algumas condições neoplásicas, talvez aqui potencializada pela ação da eletroquimioterapia (WU et al., 2014). Por outro ângulo houve involução do volume do tumor de Ehrlich nos grupos $R$, E e ER, que talvez não possa ser explicada pela redução de proliferação, avaliada pela contagem de índice mitótico, mas sim pela redução da angiogênese nos grupos envolvendo o resveratrol e por aumento da apoptose nos grupos envolvendo a eletroquimioterapia (TOUNEKTI et al., 1993).

\section{6 - CONCLUSÕES}

A eletroquimioterapia e o resveratrol determinaram redução na progressão tumoral, com tendência a um efeito superior em animais tratados com a associação dos dois procedimentos. Fenômeno possivelmente relacionado à redução na expressão de VEGFA no microambiente tumoral. 


\section{REFERÊNCIAS}

BENIZRI, E.; GINOUVÈS, A.; BERRA, E. The magic of the hypoxia-signaling cascade. Cellular and Molecular Life Sciences, v. 65, n. 7-8, p. 1133-1149, 2008.

BRANCO-PRICE, C.; ZHANG, N.; SCHNELLE, M.; EVANS, C.; KATSCHINSKI, D. M.; LIAO, D.; ELLIES, L.; JOHNSON, R. Endothelial cell HIF-1 $\alpha$ and HIF-2a differentially regulate metastatic success. Cancer Cell, v. 21, n. 1, p. 52-65, 2012.

BRUNNER, C. H. M. Equipamento e processo para aplicação de pulsos elétricos de alta voltagem para a prática de eletroquimioterapia por eletroporação no tratamento de neoplasias. PI 0903000-0, 20 mar. 2009, 26 jun. 2015

CARMELIET, P.; COLLEN, D. Vascular development and disorders: Molecular analysis and pathogenic insights. Kidney International, v. 53, n. 6, p. 1519-1549, 1998.

CUMMINS, E. P.; TAYLOR, C. T. Hypoxia-responsive transcription factors. Pflugers Archiv European Journal of Physiology, v. 450, n. 6, p. 363-371, 2005.

EVANS, C. E.; BRANCO-PRICE, C.; JOHNSON, R. S. HIF-mediated endothelial response during cancer progression. International Journal of Hematology, v. 95, n. 5, p. 471-477, 2012.

FERRARA, N.; GERBER, H.-P.; LECOUTER, J. The biology of VEGF and its receptors. Nature Medicine, v. 9, n. 6, p. 669-676, 2003.

GACCHE, R. N. Compensatory angiogenesis and tumor refractoriness.

Oncogenesis, v. 4, n. 6, p. e153, 2015. Disponível em:

<http://www.nature.com/doifinder/10.1038/oncsis.2015.14>. Acesso em: 12 jun. 2015.

GEHL, J.; SKOVSGAARD, T.; MIR, L. M. Vascular reactions to in vivo electroporation: characterization and consequences for drug and gene delivery. Biochimica et Biophysica Acta, v. 1569, n. 1-3, p. 51-8, 15 jan. 2002. Disponível em: <http://www.ncbi.nlm.nih.gov/pubmed/11853957>. Acesso em: 15 set. 2013.

GERTZ, M.; NGUYEN, G. T. T.; FISCHER, F.; SUENKEL, B.; SCHLICKER, C.; FRÄNZEL, B.; TOMASCHEWSKI, J.; ALADINI, F.; BECKER, C.; WOLTERS, D.; STEEGBORN, C. A molecular mechanism for direct sirtuin activation by resveratrol. PLoS ONE, v. 7, n. 11, p. 1-12, 2012.

GOTHELF, A.; MIR, L. M.; GEHL, J. Electrochemotherapy: results of cancer treatment using enhanced delivery of bleomycin by electroporation. Cancer Treatment Reviews, v. 29, n. 5, p. 371-387, out. 2003. Disponível em: <http://linkinghub.elsevier.com/retrieve/pii/S0305737203000732>. Acesso em: 28 fev. 2013. 
HAN, G.; XIA, J.; GAO, J.; INAGAKI, Y.; TANG, W.; KOKUDO, N. Anti-tumor effects and cellular mechanisms of resveratrol. Drug Discoveries \& Therapeutics, v. 9, n. 1, p. 1-12, 2015. Disponível em:

<https://www.jstage.jst.go.jp/article/ddt/9/1/9_2015.01007/_article>. Acesso em: 12 jun. 2015.

HANAHAN, D.; FOLKMAN, J. Patterns and emerging mechanisms of the angiogenic switch during tumorigenesis. Cell, v. 86, n. 3, p. 353-64, 9 ago. 1996. Disponível em: <http://www.ncbi.nlm.nih.gov/pubmed/8756718>. Acesso em: 12 fev. 2013.

HANAHAN, D.; WEINBERG, R. A. Hallmarks of cancer: the next generation. Cell, v. 144, n. 5, p. 646-674, 2011. Disponível em:

<http://www.ncbi.nlm.nih.gov/pubmed/21376230>. Acesso em: 12 fev. 2013.

HÖCKEL, M.; SCHLENGER, K.; MITZE, M.; SCHÄFFER, U.; VAUPEL, P. Hypoxia and radiation response in human tumors. Seminars in Radiation Oncology, v. 6, n. 1, p. 3-9, 1996. Disponível em: <http://www.ncbi.nlm.nih.gov/pubmed/10717157>. Acesso em: 14 set. 2013.

HOUTKOOPER, R. H.; PIRINEN, E.; AUWERX, J. Sirtuins as regulators of metabolism and healthspan. Nature Reviews Molecular Cell Biology, v. 13, n. 4, p. 225-238, 2012. Disponível em: <http://dx.doi.org/10.1038/nrm3293>. Acesso em: 12 mar. 2014.

JARM, T.; CEMAZAR, M.; MIKLAVCIC, D.; SERSA, G. Antivascular effects of electrochemotherapy: implications in treatment of bleeding metastases. Expert Review of Anticancer Therapy, v. 10, p. 729-746, 2010.

KOSHIJI, M.; HUANG, L. E. Dynamic balancing of the dual nature of HIF-1a for cell survival. Cell Cycle, v. 3, n. 7, p. 853-854, 2004.

MEKID, H.; TOUNEKTI, O.; SPATZ, a; CEMAZAR, M.; EL KEBIR, F. Z.; MIR, L. M. In vivo evolution of tumour cells after the generation of double-strand DNA breaks. British Journal of Cancer, v. 88, n. 11, p. 1763-71, 2 jun. 2003. Disponível em: $<$ http://www.pubmedcentral.nih.gov/articlerender.fcgi?artid=2377151\&tool=pmcentre z\&rendertype=abstract $>$. Acesso em: 19 fev. 2013.

MIR, L. M. Therapeutic perspectives of in vivo cell electropermeabilization q.

Bioelectrochemistry (Amsterdam, Netherlands), v. 53, p. 1-10, 2000.

MIR, L. M. Bases and rationale of the electrochemotherapy. European Journal of Cancer Supplements, v. 4, n. 11, p. 38-44, nov. 2006. Disponível em: <http://linkinghub.elsevier.com/retrieve/pii/S1359634906001923>. Acesso em: 14 mar. 2013.

MIR, L. M.; ORLOWSKI, S. Mechanisms of electrochemotherapy. Advanced Drug Delivery Reviews, v. 35, n. 1, p. 107-118, jan. 1999. Disponível em: <http://linkinghub.elsevier.com/retrieve/pii/S0169409X98000660>. Acesso em: 12 fev. 2013. 
MIR, L. M.; ORLOWSKI, S.; BELEHRADEK, J.; PAOLETTI, C. Electrochemotherapy potentiation of antitumour effect of bleomycin by local electric pulses. European Journal of Cancer (Oxford, England: 1990), v. 27, n. 1, p. 68-72, jan. 1991. Disponível em: <http://www.ncbi.nlm.nih.gov/pubmed/1707289>. Acesso em: 13 mar. 2010.

MIR, L. M.; TOUNEKTI, O.; ORLOWSKI, S. Bleomycin: revival of an old drug. General pharmacology, v. 27, n. 5, p. 745-8, jul. 1996. Disponível em: <http://www.ncbi.nlm.nih.gov/pubmed/8842674>. Acesso em: 12 fev. 2013.

PARK, S. Y.; JEONG, K. J.; LEE, J.; YOON, D. S.; CHOI, W. S.; KIM, Y. K.; HAN, J. W.; KIM, Y. M.; KIM, B. K.; LEE, H. Y. Hypoxia enhances LPA-induced HIF-1a and VEGF expression: Their inhibition by resveratrol. Cancer Letters, v. 258, n. 1, p. 6369, 2007.

PODDEVIN, B.; ORLOWSKI, S.; BELEHRADEK, J.; MIR, L. M. Very high cytotoxicity of bleomycin introduced into the cytosol of cells in culture. Biochemical

Pharmacology, v. 42 Suppl, p. S67-75, 11 dez. 1991. Disponível em: <http://www.ncbi.nlm.nih.gov/pubmed/1722669>. Acesso em: 27 nov. 2010.

SAMPAIO-GÓES, F. C. G.; OLIVEIRA, D. T.; DORTA, R. G.; NONOGAKI, S.; LANDMAN, G.; NISHIMOTO, I. N.; KOWALSKI, L. P. Expression of PCNA, p53, Bax, and $\mathrm{Bcl}-\mathrm{X}$ in oral poorly differentiated and basaloid squamous cell carcinoma: Relationships with prognosis. Head and Neck, v. 27, n. 11, p. 982-989, 2005.

SERSA, G.; CEMAZAR, M.; MIKLAVCIC, D. Tumor blood flow modifying effects of electrochemotherapy: a potential vascular targeted mechanism. Radiology and Oncology, v. 37, n. 1, p. 43-48, 2003.

SERSA, G.; CEMAZAR, M.; MIKLAVCIC, D.; CHAPLIN, D. J. Tumor blood flow modifying effect of electrochemotherapy with bleomycin. Anticancer Research, v. 19, n. 5B, p. 4017-22, 1999. Disponível em: <http://www.ncbi.nlm.nih.gov/pubmed/10628347>. Acesso em: 14 set. 2013.

SERSA, G.; KRZIC, M.; SENTJURC, M.; IVANUSA, T.; BERAVS, K.; KOTNIK, V.; COER, A.; SWARTZ, H. M.; CEMAZAR, M. Reduced blood flow and oxygenation in SA-1 tumours after electrochemotherapy with cisplatin. British Journal of Cancer, v. 87, n. 9, p. 1047-1054, 2002.

SOINI, Y.; PUHAKKA, a.; KAHLOS, K.; SÄILY, M.; PÄÄKKÖ, P.; KOISTINEN, P.; KINNULA, V. Endothelial nitric oxide synthase is strongly expressed in malignant mesothelioma but does not associate with vascular density or the expression of VEGF, FLK1 OR FLT1. Histopathology, v. 39, n. 2, p. 179-186, 2001.

TAFANI, M.; PUCCI, B.; RUSSO, A.; SCHITO, L.; PELLEGRINI, L.; PERRONE, G. a.; VILLANOVA, L.; SALVATORI, L.; RAVENNA, L.; PETRANGELI, E.; RUSSO, M. a. Modulators of HIF1 $\alpha$ and NFkB in cancer treatment: Is it a rational approach for controlling malignant progression? Frontiers in Pharmacology, v. 4, p. 1-12, 2013. 
TESTORI, A.; TOSTI, G.; MARTINOLI, C.; SPADOLA, G.; CATALDO, F.; VERRECCHIA, F.; BALDINI, F.; MOSCONI, M.; SOTELDO, J.; TEDESCHI, I.; PASSONI, C.; PARI, C.; PIETRO, A.; FERRUCCI, P. F. Electrochemotherapy for cutaneous and subcutaneous tumor lesions : a novel. Dermatologic Therapy, v. 23, p. 651-661, 2010.

TOUNEKTI, O.; PRON, G.; BELEHRADEK, J.; MIR, L. M. Bleomycin , an Apoptosismimetic Drug That Induces Two Types of Cell Death Depending on the Number of Molecules Internalizeds. Cancer Research, v. 53, p. 5462-5469, 1993.

WANG, G. L.; JIANG, B. H.; RUE, E. a; SEMENZA, G. L. Hypoxia-inducible factor 1 is a basic-helix-loop-helix-PAS heterodimer regulated by cellular $\mathrm{O} 2$ tension.

Proceedings of the National Academy of Sciences of the United States of America, v. 92, n. 12, p. 5510-5514, 1995.

WU, M.-L.; LI, H.; YU, L.-J.; CHEN, X.-Y.; KONG, Q.-Y.; SONG, X.; SHU, X.-H.; LIU, J. Short-term resveratrol exposure causes in vitro and in vivo growth inhibition and apoptosis of bladder cancer cells. PloS one, v. 9, n. 2, p. e89806, 2014. Disponível em:

<http://www.pubmedcentral.nih.gov/articlerender.fcgi?artid=3934942\&tool=pmcentre z\&rendertype=abstract>. Acesso em: 12 jun. 2015.

\section{CONCLUSÃO GERAL}

O método empregado e os fenômenos observados permitem concluir que a eletroquimioterapia com bleomicina por via intralesional é um método eficaz para o controle do desenvolvimento do tumor de Ehrlich na forma sólida e que a vascularização está associada a esse processo. Também permitem concluir que o resveratrol potencializa esse efeito. 


\section{REFERÊNCIAS}

BELLARD, E.; MARKELC, B.; PELOFY, S.; LE, F.; SERSA, G.; TEISSIÉ, J.; CEMAZAR, M.; GOLZIO, M. Intravital microscopy at the single vessel level brings new insights of vascular modi fi cation mechanisms induced by electropermeabilization. Journal of Controlled Release, v. 163, n. 3, p. 396-403, 2012. Disponível em: <http://dx.doi.org/10.1016/j.jconrel.2012.09.010>. Acesso em: 19 set. 2014.

BERRA, E.; BENIZRI, E.; GINOUVÈS, A.; VOLMAT, V.; ROUX, D.; POUYSSÉGUR, J. HIF prolyl-hydroxylase 2 is the key oxygen sensor setting low steady-state levels of HIF-1a in normoxia. The EMBO Journal, v. 22, n. 16, p. 4082-4090, 2003.

BRUICK, R. K.; MCKNIGHT, S. L. A conserved family of prolyl-4-hydroxylases that modify HIF. Science, v. 294, n. 5545, p. 1337-1340, 2001.

CAMONT, L.; COTTART, C. H.; RHAYEM, Y.; NIVET-ANTOINE, V.; DJELIDI, R.; COLLIN, F.; BEAUDEUX, J. L.; BONNEFONT-ROUSSELOT, D. Simple spectrophotometric assessment of the trans-/cis-resveratrol ratio in aqueous solutions. Analytica Chimica Acta, v. 634, n. 1, p. 121-128, 2009.

CARMELIET, P.; MOONS, L.; COLLEN, D. Mouse models of angiogenesis, arterial stenosis, atherosclerosis and hemostasis. Cardiovascular Research, v. 39, n. 1, p. 8-33, 1998.

CIECHANOVER, A. The ubiquitin - proteasome pathway: on protein death and cell life. The EMBO Journal, v. 17, n. 24, p. 7151-7160, 1998.

CIOBANU, F.; RADU, M.; MOISESCU, M.; SURLEAC, M.; SAVOPOL, T. ELECTROPORATION OF MALIGNANT CELLS FOR ENHANCED. Romanian Journal of Biophysics, v. 17, n. 3, p. 211-217, 2007.

COHEN-JONATHAN, E. How does radiation kill cells? Current Opinion in Chemical Biology, v. 3, n. 1, p. 77-83, 1999. Disponível em: <http://www.sciencedirect.com/science/article/pii/S1367593199800143>. Acesso em: 16 nov. 2013.

DANG, W. The controversial world of sirtuins. Drug Discovery Today:

Technologies, v. 12, p. e9-e17, 2014. Disponível em: <http://dx.doi.org/10.1016/j.ddtec.2012.08.003> Acesso em: 19 set. 2014.

D'ANDREA, A. D.; HASELTINE, W. A. Sequence specific cleavage of DNA by the antitumor antibiotics neocarzinostatin and bleomycin. Proceedings of the National Academy of Sciences of the United States of America, v. 75, n. 8, p. 3608-12, ago. 1978. Disponível em:

<http://www.pubmedcentral.nih.gov/articlerender.fcgi?artid=392834\&tool=pmcentrez \&rendertype=abstract>. Acesso em: 11 abr. 2013. 
DIMITROV, D. S.; SOWERS, A. E. Membrane electroporation--fast molecular exchange by electroosmosis. Biochimica et Biophysica Acta, v. 1022, n. 3, p. 38192, mar. 1990. Disponível em: <http://www.ncbi.nlm.nih.gov/pubmed/1690573>. Acesso em: 19 set. 2014.

DUNHAM, L. J.; STEWART, H. L. A Survey of transplantable and transmissible animal tumors. Journal of the National Cancer Institute, v. 13, n. 5, p. 1299-1377, 1 abr. 1953. Disponível em: <http://jnci.oxfordjournals.org/content/13/5/1299.short>. Acesso em: 19 set. 2014.

GERTZ, M.; NGUYEN, G. T. T.; FISCHER, F.; SUENKEL, B.; SCHLICKER, C.; FRÄNZEL, B.; TOMASCHEWSKI, J.; ALADINI, F.; BECKER, C.; WOLTERS, D.; STEEGBORN, C. A Molecular mechanism for direct sirtuin activation by resveratrol. PLoS ONE, v. 7, n. 11, p. 1-12, 2012.

GIARDINO, R.; FINI, M.; BONAZZI, V.; CADOSSI, R.; NICOLINI, A; CARPI, A. Electrochemotherapy a novel approach to the treatment of metastatic nodules on the skin and subcutaneous tissues. Biomedicine \& pharmacotherapy, v. 60, n. 8, p. 458-62, set. 2006. Disponível em: <http://www.ncbi.nlm.nih.gov/pubmed/16930935>. Acesso em: 14 mar. 2013.

GOOD, L. M.; MILLER, M. D.; HIGH, W. a. Intralesional agents in the management of cutaneous malignancy: a review. Journal of the American Academy of Dermatology, v. 64, n. 2, p. 413-22, fev. 2011. Disponível em: <http://www.ncbi.nlm.nih.gov/pubmed/20334952>. Acesso em: 23 out. 2012.

HANAHAN, D.; WEINBERG, R. A. Hallmarks of cancer: the next generation. Cell, v. 144, n. 5, p. 646-674, 2011. Disponível em: <http://www.ncbi.nlm.nih.gov/pubmed/21376230>. Acesso em: 13 nov. 2013.

HARTVEIT, F. Peritoneal exudate formation in $\mathrm{C} 3 \mathrm{H}$ mice and in mice of an unrelated closed colony. Acta Pathologica et Microbiologica Scandinavica, v. 68, n. 2, p. 194-196, 1966.

HIRSILÄ, M.; KOIVUNEN, P.; GÜNZLER, V.; KIVIRIKKO, K. I.; MYLLYHARJU, J. Characterization of the human prolyl 4-hydroxylases that modify the hypoxiainducible factor. Journal of Biological Chemistry, v. 278, n. 33, p. 30772-30780, 2003.

JARM, T.; CEMAZAR, M.; MIKLAVCIC, D.; SERSA, G. Antivascular effects of electrochemotherapy: implications in treatment of bleeding metastases. Expert Review of Anticancer Therapy, v. 10, n. 5, p. 729-46, maio 2010. Disponível em: <http://www.ncbi.nlm.nih.gov/pubmed/20470005>. Acesso em: 13 nov. 2013.

KE, Q.; COSTA, M. Hypoxia-Inducible Factor-1 (HIF-1). Molecular Pharmacology, v. 70, n. 5, p. 1469-1480, 3 ago. 2006. Disponível em: <http://molpharm.aspetjournals.org/cgi/doi/10.1124/mol.106.027029>. Acesso em: 23 mai. 2012. 
KINOSITA, K.; TSONG, T. Formation and resealing of pores of controlled sizes in human erythrocyte membrane. Nature, v. 268, n. 4, p. 438-441, 1977. Disponível em: <http://www.nature.com/nature/journal/v268/n5619/abs/268438a0.html>. Acesso em: 13 nov. 2013.

KITAMURA, A. Bleomycin-mediated electrochemotherapy in mouse NR-S1 carcinoma. Cancer Chemotherapy and Pharmacology, v. 51, n. 4, p. 359-62, abr. 2003. Disponível em: <http://www.ncbi.nlm.nih.gov/pubmed/12721764>. Acesso em: 15 nov. 2013.

KULKARNI, S. S.; CANTÓ, C. The molecular targets of resveratrol. Biochimica et Biophysica Acta (BBA) - Molecular Basis of Disease, v. 1852, n. 6, p. 1114-1123, 2014. Disponível em:

<http://linkinghub.elsevier.com/retrieve/pii/S0925443914003111>. Acesso em: 15 nov. 2012.

LEBAR, A. M.; SERSA, G.; KRANJC, S.; GROSELJ, A.; MIKLAVCIC, D. Optimisation of pulse parameters in vitro for in vivo electrochemotherapy.

Anticancer Research, v. 22, n. 3, p. 1731-6, 2002. Disponível em: <http://www.ncbi.nlm.nih.gov/pubmed/12168862>. Acesso em: 23 out. 2012.

LINO, A. M. C. D. B. Potencial angiogênico do tumor de Ehrlich na forma sólida. Estudo experimental. 2002. 70 f. Tese (Mestrado em Patologia Experimental e Comparada) - Faculdade de Medicina Veterinária e Zootecnia, Universidade de São Paulo, São Paulo, 2002.

MALI, B.; JARM, T.; SNOJ, M.; SERSA, G.; MIKLAVCIC, D. Antitumor effectiveness of electrochemotherapy: a systematic review and meta-analysis. European journal of surgical oncology : the journal of the European Society of Surgical Oncology and the British Association of Surgical Oncology, v. 39, n. 1, p. 4-16, jan. 2013a.

Disponível em: <http://www.ncbi.nlm.nih.gov/pubmed/22980492>. Acesso em: 14 fev. 2013.

MALI, B.; MIKLAVCIC, D.; CAMPANA, L. G.; CEMAZAR, M.; SERSA, G.; SNOJ, M.; JARM, T. Tumor size and effectiveness of electrochemotherapy. Radiology and Oncology, v. 47, n. 1, p. 32-41, mar. 2013b. Disponível em:

$<$ http://www.pubmedcentral.nih.gov/articlerender.fcgi?artid=3573832\&tool=pmcentre z\&rendertype=abstract>. Acesso em: 25 maio. 2013.

MAXWELL, P. H.; WIESENER, M. S.; CHANG, G. W.; CLIFFORD, S. C.; VAUX, E. C.; COCKMAN, M. E.; WYKOFF, C. C.; PUGH, C. W.; MAHER, E. R.; RATCLIFFE, P. J. The tumour suppressor protein VHL targets hypoxia-inducible factors for oxygen-dependent proteolysis. Nature, v. 399, n. 6733, p. 271-275, 1999.

MAYER, K. D. The pathogenicity of the Ehrlich ascites tumour. British Journal of Experimental Pathology, v. 47, n. 5, p. 537-544, 1966. 
METZEN, E.; BERCHNER-PFANNSCHMIDT, U.; STENGEL, P.; MARXSEN, J. H.; STOLZE, I.; KLINGER, M.; HUANG, W. Q.; WOTZLAW, C.; HELLWIG-BÜRGEL, T.; JELKMANN, W.; ACKER, H.; FANDREY, J. Intracellular localisation of human HIF-1 alpha hydroxylases: implications for oxygen sensing. Journal of Cell Science, v. 116, pt. 7, p. 1319-1326, 2003.

MIKLAVCIC, D.; PUCIHAR, G.; PAVLOVEC, M.; RIBARIC, S.; MALI, M.; MACEKLEBAR, A.; PETKOVSEK, M.; NASTRAN, J.; KRANJC, S.; CEMAZAR, M.; SERSA, $G$. The effect of high frequency electric pulses on muscle contractions and antitumor efficiency in vivo for a potential use in clinical electrochemotherapy.

Bioelectrochemistry, v. 65, n. 2, p. 121-8, fev. 2005. Disponível em: <http://www.ncbi.nlm.nih.gov/pubmed/15713562>. Acesso em: 9 maio. 2013.

MIR, L. M.; MORSLI, N.; GARBAY, J. R.; BILLARD, V.; ROBERT, C.; MARTY, M. Electrochemotherapy: a new treatment of solid tumors. Journal of experimental \& clinical cancer research : CR, v. 22, n. 4 , p. 145-8, dez. 2003. Supplement.

Disponível em:

<http://www.pubmedcentral.nih.gov/articlerender.fcgi?artid=2843684\&tool=pmcentre z\&rendertype=abstract $>$. Acesso em: 23 out. 2012.

MUÑOZ MADERO, V.; ORTEGA PÉREZ, G. Electrochemotherapy for treatment of skin and soft tissue tumours. Update and definition of its role in multimodal therapy. Clinical \& Translational Oncology, v. 13, n. 1, p. 18-24, jan. 2011. Disponível em: <http://www.ncbi.nlm.nih.gov/pubmed/21239351>. Acesso em: 23 out. 2012.

NEUMANN, E.; SCHAEFER-RIDDER, M. Gene transfer into mouse lyoma cells by electroporation in high electric fields. The European Molecular Biology

Organization Journal, v. 1, n. 7, p. 841-845, 1982. Disponível em:

<http://www.ncbi.nlm.nih.gov/pmc/articles/PMC553119/>. Acesso em: 14 nov. 2013.

NWACHUKWU, J. C.; SRINIVASAN, S.; BRUNO, N. E.; PARENT, A. A.; HUGHES, T. S.; POLLOCK, J. a.; GJYSHI, O.; CAVETT, V.; NOWAK, J.; GARCIA-ORDONEZ, R. D.; HOUTMAN, R.; GRIFFIN, P. R.; KOJETIN, D. J.; KATZENELLENBOGEN, J. A.; CONKRIGHT, M. D.; NETTLES, K. W. Resveratrol modulates the inflammatory response via an estrogen receptor-signal integration network. eLife, v. 2014, n. 3, p.1-30, 2014.

OKINO, M.; MOHRI, H. Effects of a high-voltage electrical impulse and an anticancer drug on in vivo growing tumors. Japanese Journal of Cancer Research, v. 78, n. 12, 1987. Disponível em: <http://www.ncbi.nlm.nih.gov/pubmed/2448275>. Acesso em: 13 nov. 2013.

ORLOWSKI, S.; BELEHRADEY JR, J.; PAOLETTI, C.; MIR, L. M. Transient electropermeabilization. Biochemical Pharmacology, v. 37, n. 24, p. 4727-4733, 1988.

POLTORAK, Z.; COHEN, T.; SIVAN, R.; KANDELIS, Y.; SPIRA, G.; VLODAVSKY, I.; KESHET, E.; NEUFELD, G. VEGF 145 , A secreted vascular endothelial growth factor isoform that binds to extracellular matrix. The Journal of Biological

Chemistry, v. 272, n. 11, p. 7151-7158, 1997. Acesso em: 13 nov. 2013. 
POVIRK, L. F.; HAN, Y. H.; STEIGHNER, R. J. Structure of bleomycin-induced DNA double-strand breaks: predominance of blunt ends and single-base 5' extensions.

Biochemistry, v. 28, n. 14, p. 5808-14, 11 jul. 1989. Disponível em: <http://www.ncbi.nlm.nih.gov/pubmed/2476175>. Acesso em: 13 jun. 2013.

PRON, G.; BELEHRADEY JR, J.; MIR, L. M. Identification of a plasma membrane protein that specifically binds bleomycin. Biochemical and Biophysical Research Communications, v. 194, n. 1, p. 333-337, 1993.

PUCIHAR, G.; KOTNIK, T.; MIKLAVCIC, D.; TEISSIÉ, J. Kinetics of transmembrane transport of small molecules into electropermeabilized cells. Biophysical Journal, v. 95, n. 6, p. 2837-48, 15 set. 2008. Disponível em:

<http://www.pubmedcentral.nih.gov/articlerender.fcgi?artid=2527253\&tool=pmcentre z\&rendertype=abstract>. Acesso em: 15 nov. 2013.

REED, S. D.; FULMER, A.; BUCKHOLZ, J.; ZHANG, B.; CUTRERA, J.; SHIOMITSU, K.; LI, S. Bleomycin/interleukin-12 electrochemogene therapy for treating naturally occurring spontaneous neoplasms in dogs. Cancer Gene Therapy, v. 17, n. 7, p. 457-64, jul. 2010. Disponível em:

$<$ http://www.pubmedcentral.nih.gov/articlerender.fcgi?artid=3148143\&tool=pmcentre z\&rendertype=abstract>. Acesso em: 14 nov. 2013.

ROLS, M. P.; TEISSIÉ, J. Electropermeabilization of mammalian cells. Quantitative analysis of the phenomenon. Biophysical Journal, v. 58, n. 5, p. 1089-1098, nov. 1990. Disponível em:

<http://linkinghub.elsevier.com/retrieve/pii/S0006349590824516>. Acesso em: 25 nov. 2014.

SALE, A.; HAMILTON, W. Effects of high electric fields on microorganisms: I. Killing of bacteria and yeasts. Biochimica et Biophysica Acta, v. 148, p. 781-788, 1967. Disponível em:

<http://www.sciencedirect.com/science/article/pii/0304416567900529>. Acesso em: 13 nov. 2013.

SATKAUSKAS, S.; BATIUSKAITE, D.; SALOMSKAITE-DAVALGIENE, S.; VENSLAUSKAS, M. S. Effectiveness of tumor electrochemotherapy as a function of electric pulse strength and duration. Bioelectrochemistry, v. 65, n. 2, p. 105-11, fev. 2005. Disponível em: <http://www.ncbi.nlm.nih.gov/pubmed/15713560>. Acesso em: 23 out. 2012.

SEBTI, S. M.; MIGNANO, J. E.; JANI, J. P.; SRIMATKANDADA, S.; LAZO, J. S. Bleomycin hydrolase: molecular cloning, sequencing, and biochemical studies reveal membership in the cysteine proteinase family. Biochemistry, v. 28, n. 16, p. 6544-8, 8 ago. 1989. Disponível em: <http://www.ncbi.nlm.nih.gov/pubmed/2477059>.

Acesso em: 13 nov. 2013. 
SEMENZA, G. L. Targeting HIF-1 for cancer therapy. Nature Reviews. Cancer, v. 3, n. 10, p. 721-732, 2003. Acesso em: 13 nov. 2013.

SERSA, G. The state-of-the-art of electrochemotherapy before the ESOPE study; advantages and clinical uses. European Journal of Cancer Supplements, v. 4, n. 11, p. 52-59, nov. 2006. Disponível em:

<http://linkinghub.elsevier.com/retrieve/pii/S1359634906001947>. Acesso em: 15 nov. 2013.

SERSA, G.; CEMAZAR, M.; PARKINS, C. S.; CHAPLIN, D. J. Tumour Blood Flow Changes Induced by Application of Electric Pulses. European Journal of Cancer, v. 35, n. 4, p. 672-677, 1999.

SERSA, G.; CEMAZAR, M.; RUDOLF, Z. Electrochemotherapy : advantages and drawbacks in treatment of cancer patients Review Article. Cancer Therapy, v. 1, p. 133-142, 2003.

SHANKAYI, Z.; FIROOZABADI, S. M. P. Tumor growth inhibited by low-voltage amplitude and 5-kHz frequency electrochemotherapy. The Journal of Membrane Biology, v. 244, n. 3, p. 121-8, dez. 2011. Disponível em:

<http://www.ncbi.nlm.nih.gov/pubmed/22057904>. Acesso em: 16 out. 2012.

SINGH, C. K.; NDIAYE, M. a.; AHMAD, N. Resveratrol and cancer: Challenges for clinical translation. Biochimica et Biophysica Acta (BBA) - Molecular Basis of Disease, v. 1852, n. 6, p. 1178-1185, 2014. Disponível em: <http://linkinghub.elsevier.com/retrieve/pii/S0925443914003342>. Acesso em: 27 abr. 2013.

SPUGNINI, E. P.; DOTSINSKY, I.; MUDROV, N.; CARDOSI, G.; CITRO, G.; D'AVINO, A; BALDI, A. Biphasic pulses enhance bleomycin efficacy in a spontaneous canine perianal tumors model. Journal of Experimental \& Clinical Cancer Research: CR, v. 26, n. 4, p. 483-7, dez. 2007. Disponível em: <http://www.ncbi.nlm.nih.gov/pubmed/18365542>. Acesso em: 15 mai. 2012.

SPUGNINI, E. P.; PORRELLO, A. Potentiation of chemotherapy in companion animals with spontaneous large neoplasms by application of biphasic electric pulses. Journal of Experimental \& Clinical Cancer Research, v. 22, n. 4, p. 571-80, dez. 2003. Disponível em: <http://www.ncbi.nlm.nih.gov/pubmed/15053299>. Acesso em: 13 nov. 2013.

TEISSIÉ, J.; ESCOFFRE, J. M.; PAGANIN, A.; CHABOT, S.; BELLARD, E.; WASUNGU, L.; ROLS, M. P.; GOLZIO, M. Drug delivery by electropulsation: Recent developments in oncology. International Journal of Pharmaceutics, v. 423, n. 1, p. 3-6, 14 fev. 2012. Disponível em: <http://dx.doi.org/10.1016/j.jpharm.2011.09.038>. Acesso em: 15 nov. 2013.

TEISSIE, J.; TSONG, T. Y. Electric field induced transient pores in phospholipid bilayer vesicles. Biochemistry, v. 20, n. 6, p. 1548-54, 17 mar. 1981. Disponível em: <http://www.ncbi.nlm.nih.gov/pubmed/6261800>. Acesso em: 13 nov. 2013. 
TISCHER, E.; MITCHELL, R.; HARTMAN, T.; SILVA, M.; GOSPODAROWICZS, D.; FIDDES, J. C.; ABRAHAMLL, J. A. The Human Gene for Vascular Endothelial Growth Factor. The Journal of Biological Chemistry, v. 266, n. 18, p. 1194711954, 1991.

TOUNEKTI, O.; KENANI, A; FORAY, N.; ORLOWSKI, S.; MIR, L. M. The ratio of single- to double-strand DNA breaks and their absolute values determine cell death pathway. British Journal of Cancer, v. 84, n. 9, p. 1272-9, 4 maio 2001. Disponível em:

$<$ http://www.pubmedcentral.nih.gov/articlerender.fcgi?artid=2363894\&tool=pmcentre z\&rendertype=abstract>. Acesso em: 13 nov. 2013.

VERLENGIA, R. Estudo do perfil de eletroforese e imunoeletroforese em camundongos portadores do tumor de ehrlich. 1994. $129 \mathrm{f}$. Tese (Mestrado em Ciências) - Faculdade de Odontologia de Piracicaba, Universidade Estadual de Campinas,Piracicaba, 1994. 